\title{
Selenium Biofortification and Interaction With Other Elements in Plants: A Review
}

\author{
Xinbin Zhou', Jing Yang ${ }^{1}$, Herbert J. Kronzucker ${ }^{2}$ and Weiming Shi3* \\ ${ }^{1}$ College of Resources and Environment, Southwest University, Chongqing, China, ${ }^{2}$ Faculty of Land and Food Systems, \\ University of British Columbia, Vancouver, BC, Canada, ${ }^{3}$ State Key Laboratory of Soil and Sustainable Agriculture, Institute \\ of Soil Science, Chinese Academy of Sciences, Nanjing, China
}

Selenium (Se) is an essential element for humans and animals and its deficiency in the diet is a global problem. Crop plants are the main source of Se for consumers. Therefore, there is much interest in understanding the factors that govern the accumulation and distribution of $\mathrm{Se}$ in the tissues of crop plants and the mechanisms of interaction of Se absorption and accumulation with other elements, especially with a view toward optimizing Se biofortification. An ideal crop for human consumption is rich in essential nutrient elements such as Se, while showing reduced accumulation of toxic elements in

OPEN ACCESS

Edited by:

Jorge Rodriguez-Celma, John Innes Centre, United Kingdom

Reviewed by: Naoko Ohkama-Ohtsu, Tokyo University of Agriculture and Technology, Japan Zhi-Qing Lin,

Southern Illinois University Edwardsville, United States

${ }^{*}$ Correspondence: Weiming Shi wmshi@issas.ac.cn

Specialty section: This article was submitted to Plant Nutrition,

a section of the journal Frontiers in Plant Science

Received: 23 July 2020 Accepted: 16 October 2020 Published: 05 November 2020

Citation:

Zhou X, Yang J, Kronzucker HJ and Shi W (2020) Selenium Biofortification and Interaction With Other Elements in Plants: A Review. Front. Plant Sci. 11:586421. doi: 10.3389/fp/s.2020.586421 its edible parts. This review focuses on (a) summarizing the nutritional functions of Se and the current understanding of Se uptake by plant roots, translocation of Se from roots to shoots, and accumulation of Se in grains; and (b) discussing the influence of nitrogen $(N)$, phosphorus $(P)$, and sulfur $(S)$ on the biofortification of Se. In addition, we discuss interactions of Se with major toxicant metals $(\mathrm{Hg}$, As, and $\mathrm{Cd}$ ) frequently present in soil. We highlight key challenges in the quest to improve Se biofortification, with a focus on both agronomic practice and human health.

Keywords: Se, biofortification, nutrient elements, heavy metal, interaction effect

\section{INTRODUCTION}

Se is an essential trace element for human and animal health, where it can be covalently incorporated into amino acids, chiefly selenocysteine (SeCys) and selenomethionine (SeMet), and acts as a cofactor for antioxidant enzymes such as glutathione peroxidase, and, in these chemical forms, is involved in the maintenance of the immune system, regulation of thyroid function, brain cognitive function, general antioxidant and detoxification capacity, and anti-cancer and anti-viral effects have also been documented (Hatfield et al., 2014; Ullah et al., 2019). Se deficiency in the human body can lead to serious medical complications, including cataracts, endothelial dysfunction and cardiovascular disease, cardiomyopathy, osteochondropathy, poor immune function, cognitive decline, and even cancer (Natasha et al., 2018; Newman et al., 2019). However, more than about 15\% of the world's population suffer from Se deficiency, including in many regions of China, Oceania, Africa, and Europe (Tan et al., 2016; Schiavon and Pilon-Smits, 2017; Dinh et al., 2018). Plants are the major dietary source of Se for humans, but Se levels in cereals such as rice and wheat are generally low (Zhu et al., 2009; Williams et al., 2009). Se deficiency is a long-standing public health problem (Gao et al., 2018; D’Amato et al., 2018). In China, low Se concentrations in staple food has been linked to decreased Se concentrations in hair (Li et al., 2014; Dinh et al., 2018). Se deficiency 
can be countered with Se-enriched food. Biofortification of crops is an economically viable and safe agricultural technique, and can be aimed at increasing Se concentration in the edible parts of crops, thereby overcoming Se deficiency in the diet (White and Broadley, 2009).

In plants, moderate $\mathrm{Se}$ is not considered essential but acts as a clearly beneficial element and can promote plant growth (Pilon-Smits et al., 2017; Jia et al., 2018). It has been shown to be involved in the regulation of photosynthesis and respiration, stress resistance, antioxidant capacity, abiotic stress tolerance, and alleviation of heavy metal stresses (Ulhassan et al., 2019; Dai et al., 2019; Duan et al., 2019). It is important to point out that there is a narrow range of Se accumulation in tissues within which Se deficiency transitions to toxicity in humans, animals, and plants. Excessive amounts of selenium can cause toxicity to all organisms. This article focuses on the range of Se doses in Se applications below the toxicity threshold.

In recent years, pollution by heavy metals, especially As, $\mathrm{Hg}$, and $\mathrm{Cd}$, which possess relatively high mobility in agricultural soil, has caused widespread concern. These metals are readily absorbed by most plants and pose a potential health risk to livestock animals and humans as they enter the food chain (Zhao F. et al., 2010). In the past 10 years, great progress has been made in reducing heavy metal absorption and accumulation in grains by virtue of Se soil amendments (Zhang H. et al., 2014; Tran et al., 2018a; Camara et al., 2019; Li et al., 2019a).

To sum up, Se is of great nutritional significance in humans and of significant importance in reducing the bioconcentration of heavy metals in the food chain (Dinh et al., 2019). An ideal crop is one with high bioavailability of essential elements such as Se, but with reduced accumulation of metals such as $\mathrm{Cd}$, As, and $\mathrm{Hg}$ in the edible parts (Huang S. et al., 2020). Therefore, in this review, we provide a summary of our current understanding of the mechanisms of Se uptake by plants, Se transport between root to shoot, within-plant Se distribution between organs and sequestration within edible parts, and of the principal interaction mechanisms with macronutrient elements and heavy metals, with an emphasis on the implications for Se biofortification and reductions in the toxic metal load of crop plants.

\section{PATHWAYS OF SE UPTAKE FROM THE SOIL TO PLANT ROOTS}

Plant roots can absorb inorganic Se as Se(VI) (selenate), Se(IV) (selenite), elemental Se(0) and organic Se species, such as SeCys and SeMet, but cannot absorb Se(-II) selenide (Wu et al., 2015; White, 2016). There are different forms of Se in soils as a function of $\mathrm{pH}$ and Eh. In oxic soils $(\mathrm{pH}+\mathrm{pE}>15)$, selenate is the most abundant form, while, in anaerobic soils with a neutral to acidic $\mathrm{pH}(\mathrm{pH}+\mathrm{pE}=7.5-15)$, selenite $\left(\mathrm{SeO}_{3}{ }^{2-} ; \mathrm{HSeO}_{3}{ }^{-} ; \mathrm{H}_{2} \mathrm{SeO}_{3}\right.$ ) is the most abundant form (White, 2018). Nutrients absorbed by plants mainly come from the rhizosphere, and the local conditions in the rhizosphere can influence the bioavailability of Se to plants (Zhou et al., 2007; Chen et al., 2010). Plant roots selectively take up different forms of Se by different mechanisms, and the mobility and metabolism of different forms of Se in plants lead to different seleno-compounds.

\section{Selenate Uptake}

Se and sulfur (S) are both group-16 "chalcogens" in the periodic table, meaning they have similar ionic radii, covalent radii, and chemical properties (White, 2016). Indeed, selenate enters plant roots using sulfate transporters (Gupta and Gupta, 2017). In Arabidopsis thaliana, SULTR1;1 and SULTR1;2 are the two highaffinity sulfate transporters resident in the plasma membrane that can facilitate the transport of $\mathrm{Se}(\mathrm{VI})$ (Schiavon et al., 2015). Different plant roots have different transporters for $\mathrm{Se}(\mathrm{VI})$ absorption. At present, no specific Se(VI) transporter has been found in any organism, but the results of bioinformatics analysis suggest that specific $\mathrm{Se}(\mathrm{VI})$ transporters may exist in Se hyperaccumulators (Harris et al., 2014). However, no candidate for a specific $\mathrm{Se}(\mathrm{VI})$ transporter has, to date, been identified.

\section{Selenite Uptake}

Selenite is a weak acid, which can exist in different forms under varying $\mathrm{pH}$ and Eh (Zhou et al., 2018; White, 2018). Different absorption mechanisms for $\mathrm{Se}(\mathrm{VI})$ appear to be in operation under different $\mathrm{pH}$ regimes. Zhao X. et al. (2010) found that, under acidic conditions, the rice silicon transporter OsNIP2;1 absorbs $\mathrm{H}_{2} \mathrm{SeO}_{3}$. In slightly acidic paddy soils, selenite prevails in the form of $\mathrm{HSeO}_{3}{ }^{-}$, which is structurally similar to $\mathrm{H}_{2} \mathrm{PO}_{4}{ }^{-}$. In keeping with this, a phosphate transporter OsPT2 has been found to catalyze the transport of $\mathrm{HSeO}_{3}{ }^{-}$(Zhang L. et al., 2014; Figure 1). Song et al. (2017) showed, in transgenic tobacco lines, that the absorption of phosphate and Se accumulation in shoots is improved by over-expression of OsPT8, but it remains unclear whether this is a more universal transport relationship between the two elements in plants. It emerges that several parallel selenite absorption pathways exist in plants, only some of which are related to $\mathrm{P}$ absorption, and very few genes related to Se absorption in plant have hitherto been explored, highlighting the need for much more concentrated research on the molecular mechanism of Se uptake, transport, and metabolism (Table 1 and Figure 1).

\section{Organic Se Species Uptake}

Compared with studies on inorganic Se, there is comparatively much less research to date on the absorption and transport of organic forms of Se by plants. Kikkert and Berkelaar (2013) showed that SeCys and SeMet were both taken up at rates that were some 20-fold higher than those observed for selenate or selenite. Se-amino acids, in particular, are likely to enter plant cells via amino acid transporters (AA Tr.) (Figure 1; Lima et al., 2018; Schiavon et al., 2020). It has therefore been reasoned that SeCys and SeMet can be taken up by this amino acid transporter as well. As there are many classes of amino acid transporters, it is reasonable to hypothesize that other amino acid transporters will also be involved in the absorption of organic forms of Se, but work in this area remains scant. 


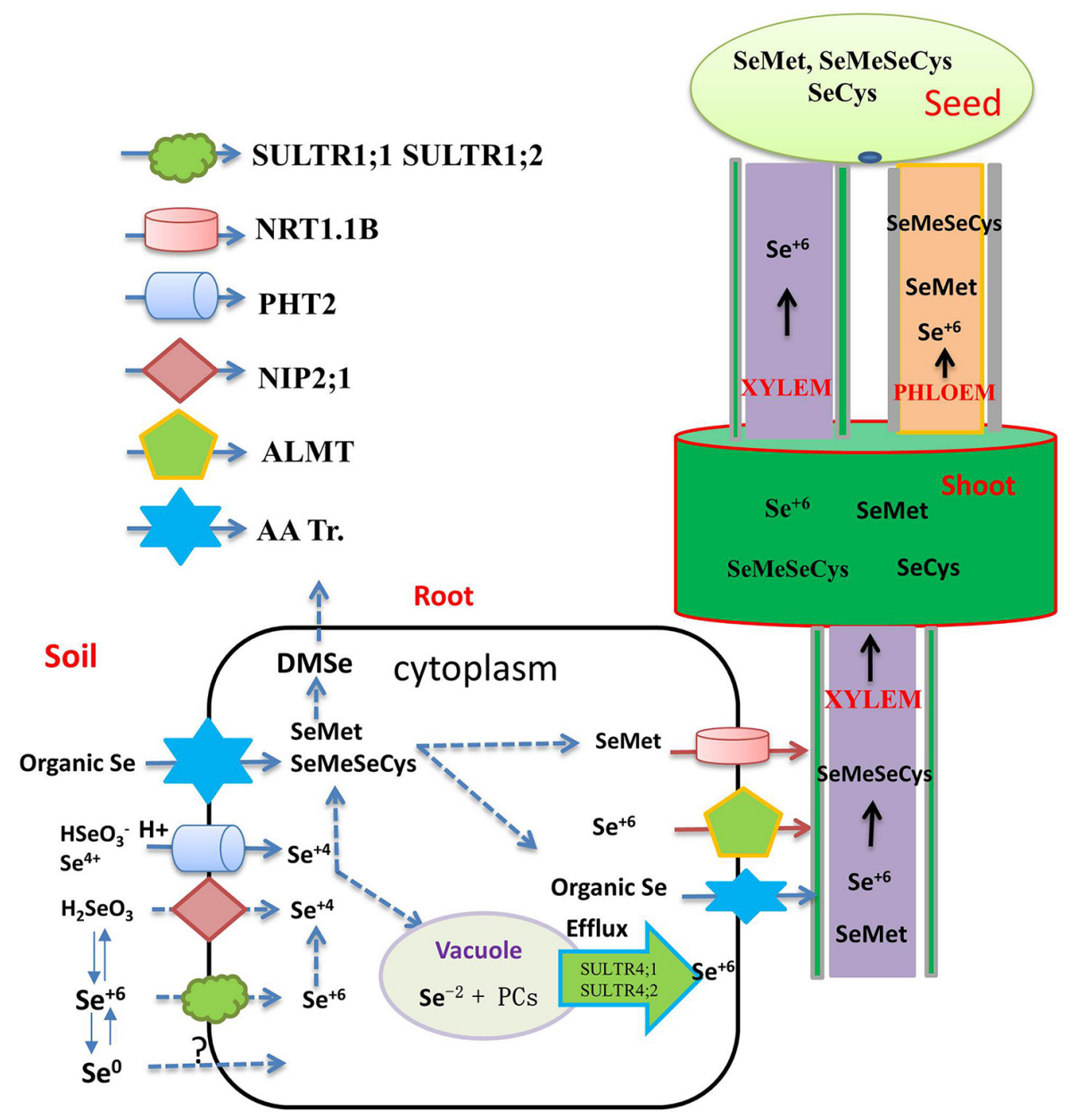

FIGURE 1 | Flow diagram representing the transporters involved in the uptake, translocation, and accumulation of different selenium species through xylem and phloem to the grain. The main transporters involved in inorganic Se uptake by plants (SULTR1;1, SULTR1;2 for selenate, NIP2;1, PT2 and PT8 for selenite, AA Tr. For amino acids). Organic Se forms are transported into the xylem via amino acid permeases (AA Tr.) and delivered to the shoots. Selenate is the major Se species present in the xylem and loaded into the xylem by SULTR2;1. Organic-Se compounds are transported into the seed via the phloem, while selenate is transported via both xylem and phloem. The translocation of SeMet to the seeds is enhanced by overexpression of the NRT1;1B transporter.

TABLE 1 | The main genes involved in Se uptake, transport, and metabolism in plant.

\section{Function \\ Gene category}

\section{Se uptake transport protein}

$\mathrm{H}_{2} \mathrm{SeO}_{3}$ uptake by root

$\mathrm{HSeO}_{3}{ }^{-}$uptake by root

$\mathrm{Se}(\mathrm{VI})$ uptake by root

Selenite uptake and transport by root

Selenite and $\mathrm{Pi}$ uptake in root of tobacco

SeMet translocation from roots to shoots and grain

\section{Key enzymes of Se metabolism pathway}

Catalyze Se(VI) into APSe

Catalyze APSe into Se(IV)

$\mathrm{Se}(\mathrm{IV})$ reduction to $\mathrm{Se}(\mathrm{II}-)$

Catalyze Se(IV) into SeCys

Catalyze the synthesis of other organic species from Se-Cys
Silicon influx transporter Phosphate transporter

Sulfate transporter

Phosphate transporter

Phosphate transporter

Rice peptide transporter (PTR)

ATP sulfurylase

APS reductase

Sulfite reductase enzyme

Selenomethyltransferase

Cystathionine- $\gamma$-synthase
Gene name

References

OsNIP2; 1

OsPT2

AtSULTR1;2

OsPT8

NtPT2

NRT1.1B

APS

$A P R$

SiR

SMT

CGS
Zhao X. et al., 2010

Zhang L. et al., 2014

Ei et al., 2007

Song et al., 2017

Jia et al., 2018

Zhang et al., 2019

Sors et al., 2005

Sors et al., 2005

White, 2018

Chauhan et al., 2019

White, 2018 


\section{SE TRANSLOCATION FROM ROOT TO SHOOT}

Inorganic forms of Se absorbed by plants are transported from the root to the shoot through the xylem. The transport process depends on the form of externally supplied Se. Se(VI) can be easily absorbed and transported by the xylem, and then distributed further to reproductive organs by the phloem (Carey et al., 2012). Members of the ALMT transporter family, such as AtALMT12, are thought to load Se(VI) into the xylem sap, and $\mathrm{Se}(\mathrm{VI})$ is the major Se species present in the xylem, although small amounts of SeMet and SeOMet are also found (White, 2018; Figure 1).

In most plants, $\mathrm{Se}(\mathrm{VI})$ enters mesophyll cells through the SULTR transporter, and its accumulation then occurs in the vacuole. The transporter responsible for the entry of $\mathrm{Se}(\mathrm{VI})$ across the tonoplast into the vacuole remains undefined, but homologs of AtSULTR4;1 and AtSLUTR4;2 have been proposed to act as efflux transporters for Se(VI) exiting vacuoles (White, 2016). $\mathrm{Se}(\mathrm{VI})$ is reduced to $\mathrm{Se}(\mathrm{IV})$ in plant leaves, and, once reduced, Se is then incorporated into organic Se compounds and distributed to other tissues. Carey et al. (2012) suggested that Se(VI), SeMet, and Se-methylselenocysteine (MeSeCys) transported via the xylem are then readily redistributed to sink organs via the phloem. In Arabidopsis, AtSULTR1;3 and AtSULTR2;2 seem to promote $\mathrm{Se}(\mathrm{VI})$ to enter the phloem, and the expression of genes encoding AtSULTR1;3 and AtSULTR2;2 is upregulated by Se accumulation (Wang et al., 2018).

Following Se(IV) absorption by roots, rapid assimilation into organic forms, including SeMet and MeSeCys, can occur. These seleno amino acids mainly accumulate in the root, with only a small portion transferred to the shoot, rendering the root system the site of higher bioconcentration of the element (Winkel et al., 2015), a potential impediment to Se biofortification of crop plants, as most edible parts are above-ground.

The transport of ions or molecules to the aboveground plant tissues depends on the xylem loading rate and the rate of transpiration (Renkema et al., 2012). Kikkert and Berkelaar (2013) verified that different Se species are transported at significantly different rates in canola and wheat, in the order: $\mathrm{Se}(\mathrm{VI})>\mathrm{SeMet}>\mathrm{Se}(\mathrm{IV}) / \mathrm{SeCys}$. This primary Se absorption difference is due to regulation of transporters resident in the plasma membrane of root cells. Recently, Liang et al. (2019) demonstrated that a low concentration of Se in the supply medium induces the expression of OsNIP 2;1, which may serve as a strong positive regulator of Se transport in rice.

\section{LONG-DISTANCE TRANSLOCATION AND SE ACCUMULATION IN ABOVEGROUND TISSUES OF PLANTS}

Long-distance Se transport is important for regulating Se accumulation and increasing Se concentration in particular in crop-plant tissues that are most often consumed by livestock and by humans. Se speciation in edible parts differs among plants. For example, Se in rice grains is mainly in the form of SeMet, followed by SeMeSeCys, and SeCys (Carey et al., 2012). MeSeSeCys, $\mathrm{Se}(\mathrm{VI})$, and $\mathrm{Se}(\mathrm{IV})$ are the main Se compounds in the aboveground tissues of broccoli (Wu et al., 2015). In staple food crops such as the grain crops wheat, barley, and rye, SeMet is the main Se compound (Poblaciones et al., 2014), while in rice grains, SeMet is the main Se species, accounting for $82.9 \%$ of total Se, followed by MeSeCys accounting for $6.2 \%$ of total Se, and SeCys accounting for $2.8-6.3 \%$ of total Se (Sun et al., 2010). Carey et al. (2012) have suggested that organic Se (SeMet and SeMeSeCys) is transported to the grain exclusively via the phloem, while inorganic Se is transported to the grain by both phloem and xylem. Different Se forms have different nutritional value to humans, among which SeMeSeCys has superior anti-cancer properties (Roman et al., 2014). Thus, with a view to human health, increasing the concentration of SeMeSeCys in the edible parts of crops by means of biofortification is a major goal. With the refinement of molecular biology techniques, and on the basis of studying the mechanisms of Se transport and metabolism, it has become possible to achieve overexpression of target genes related to Se enrichment in specific plant tissues, such as grains, so as to improve the Se concentration of crops. Zhou et al. (2017c) found that Se-enriched Xiushui 48 rice can transport more organic Se from flag leaves to grains than a non-Se-enriched variety, explaining the pronounced difference between these rice varieties in their grain Se concentration. It is still unknown whether Se transporter protein activity and expression levels in Se-rich varieties are higher than those in non-Se-rich varieties. NRT1.1B is responsible for transporting SeMet to rice grains, thus improving grain accumulation of Se, and transgenic lines overexpressing NRT1.1B have significantly increased grain Se concentration (Zhang et al., 2019; Figure 1). These above studies not only deepen our understanding of Se uptake and translocation mechanisms, but also provide a theoretical basis for breeding Se-enriched crop varieties.

\section{METABOLISM OF SE IN PLANTS}

Se and S share the same metabolic pathway in plants. Se absorbed by roots is delivered to leaf chloroplasts via the xylem. Once inside chloroplasts, $\mathrm{Se}(\mathrm{VI})$ is reduced to adenosine phosphoselenate (APSe) under ATP sulfurylase (APS), and the reduction to $\mathrm{Se}(\mathrm{IV})$ is catalyzed by adenosine phosphoselenate reductase (APR), using glutathione (GSH) as the electron donor; this step is the rate-limiting step for Se metabolism into organic components. Se(IV) reduction to $\mathrm{Se}(\mathrm{II}-)$ is performed by the sulfite reductase enzyme (SiR) (White, 2018). Se(II-) can then react with O-acetylserine (OAS) to form Se-cysteine (SeCys) (White, 2018). Alternatively, SeCys can be formed directly from selenite by the selenomethyltransferase enzyme (SMT) (Chauhan et al., 2019). Further transformation of SeCys into other organic species can occur via cystathionine$\gamma$-synthase (CGS), cystathionine- $\beta$-lyase (C $\beta \mathrm{L})$, SeCys methyl synthase (SMT) methylation, with the products of SeMet and MeSeCys and MeSeMet. SeMet and MeSeCys can then be further 
metabolized into selenoproteins and volatile Se species such as dimethylselenide (DMeSe) or dimethyldiselenide (DMeDSe) (Gupta and Gupta, 2017; White, 2018).

In recent years, a host of genes coding for Se uptake, transport, and metabolism in plants have been identified (Table 1). Manipulating, and capitalizing on the natural variation in, the expression of these genes will play a vital role in improving the accumulation, tissue-specific distribution, and chemical speciation of Se in plants. Understanding the interplay of the key genes is urgent so as to afford the tools for improvement in the biofortification potential of crops that will benefit animal and human nutrition.

\section{SE INTERACTIONS WITH MACRONUTRIENT ELEMENTS (N, P, AND S)}

\section{The Role of Nitrogen in the Regulation of Se Bioavailability and Accumulation}

$\mathrm{N}$ fertilizer plays a central role in increasing crop yield and improving crop quality in all forms of intensive agriculture (Cui et al., 2010). The effect of $\mathrm{N}$ on plant Se absorption is bidirectional (Table 2). Reis et al. (2018) demonstrated that, in rice, with increasing $\mathrm{N}$-fertilizer application, the Se concentration in grains increased. Similarly, Chen et al. (2016) showed that high $\mathrm{N}$ fertilization can promote uptake and translocation of Se in wheat on low-Se soils. This interaction between $\mathrm{N}$ and Se can be explained as follows: (1) $\mathrm{N}$ application activates $\mathrm{S}$ metabolism and increases $\mathrm{S}$ assimilation by increasing $\mathrm{O}$-acetyl serine, a key regulator of $\mathrm{S}$ metabolism in cysteine synthesis in higher plants, and then increases the synthesis of cysteine and protein (Kim et al., 1999). Se and S use the same metabolic pathway in plants. Therefore, $\mathrm{N}$ application can also promote plant Se absorption, and Se can then be further metabolized into selenoproteins. (2) N fertilizer promotes growth, thereby promoting the absorption of $\mathrm{P}, \mathrm{K}, \mathrm{S}$, and other mineral elements, including Se, by the root system (Chen et al., 2012); (3) N fertilizer applied to the soil mainly exists in the form of nitrate- $\mathrm{N}\left(\mathrm{NO}_{3}-\mathrm{N}\right)$, and $\mathrm{NO}_{3}{ }^{-}$, at high doses, can dislodge Se anions from the surface of soil particles, leading to an increase of $\mathrm{SeO}_{4}{ }^{2-}$ concentration in soil solution, in turn promoting Se uptake (Dinh et al., 2018). Similarly, Klikocka et al. (2017) observed that Se concentration and uptake in spring wheat grain increased significantly with increasing $\mathrm{N}$-fertilizer application. The results show that $\mathrm{N}$ applications are helpful for plants in terms of increasing Se uptake by roots.

However, N-fertilizer applications can also lead to decreases in Se concentration. Morlon et al. (2006) reported a significant inhibition of Se(IV) uptake by $\mathrm{NO}_{3}-\mathrm{N}$ in the alga Chlamydomonas reinhardtii. One mechanism by which such inhibition might occur for higher plants in soils lies in the fact that high doses of $\mathrm{N}$ can promote soil acidification (Guo et al., 2010), thereby reducing Se availability by virtue of the formation of less plant-available ferric-iron-selenite complexes (Gupta and Gupta, 2000). Moreover, Xu et al. (2010) demonstrated that anions such as $\mathrm{NO}_{3}{ }^{-}, \mathrm{SeO}_{4}{ }^{2-}$ or $\mathrm{SeO}_{3}{ }^{2-}$, can antagonize, or compete with, each other's absorption individually and collectively. In addition, under low-nitrate conditions, plant Se concentration has been shown to be positively correlated with soil-extractable $\mathrm{NO}_{3}-\mathrm{N}$ concentration, whereas, under high-nitrogen conditions (more than $600 \mathrm{mg} \mathrm{kg}^{-1}$ ), plant Se concentration was negatively correlated with soil-extractable $\mathrm{NO}_{3}-\mathrm{N}$ (Li et al., 2015). The results show that high-N applications can at times reduce Se uptake by plants.

Therefore, $\mathrm{N}$ fertilizers can have two-way effects on the bioavailablity of Se, by diverse mechanisms. Clearly, the relationship between tissue Se accumulation in plants and $\mathrm{N}$ supply on different soil types and under varying N-nutrientmanagement regimes in the field needs dedicated examination (Dinh et al., 2018).

\section{The Role of Phosphorus in the Regulation of Se Bioavailability and Accumulation}

Although $\mathrm{P}$ and Se are non-congeners, both are absorbed by plants when present in the anionic form in the soil, and they have similar ionic radii and physical and chemical properties. Hence, competition with oxyacid anions in soil is expected to affect the absorption and accumulation of Se by plants. However, current literature reports on the relationship between plant Se uptake and $\mathrm{P}$ levels and acquisition have shown conflicting results (Table 2). The hydrogen phosphate ion can significantly reduce Se(IV) absorption from the soil by competition, however, increasing soil-solution Se concentrations, while Se in soil solution is easily absorbed by plants (Lee et al., 2011; Zhou et al., 2015). Zhang et al. (2017) reported that P fertilization together with $\mathrm{Se}(\mathrm{IV})$ could significantly reduce Se accumulation in wheat in calcareous soil, but in the case of $\mathrm{P}$ fertilization together with $\mathrm{Se}(\mathrm{VI})$, there was increased Se accumulation in wheat. Such differences show that the effect of $\mathrm{P}$ application on plant Se uptake and accumulation depends on the type of Se speciation in the soil (Zhang L. et al., 2014). The reason is that P improves bioavailability of $\mathrm{Se}(\mathrm{VI})$, but $\mathrm{P}$ application lowers soil $\mathrm{pH}$ and activates soil iron ions, and iron has a high affinity for Se, converting soluble Se in the soil into iron oxide Se and organic Se. These two forms of Se are difficult for plants to absorb, i.e., Se(IV) absorption by crops is reduced under combined applications of $\mathrm{P}$ fertilizer and Se(IV) (Szlachta et al., 2012). On the other hand, $\mathrm{P}$ fertilizer activated Fe-oxide-bound Se and organic-matterbound Se in calcareous soil, and increased bioavailability and Se concentration in wheat (Zhang et al., 2017). In addition, the influence of $\mathrm{P}$ application on Se uptake and accumulation in plants depends on the rate of the P application (Liu et al., 2018; Li et al., 2019b). Nie et al. (2020) also demonstrated that all Se fractions (total, organic, inorganic) in the grain of winter wheat were significantly decreased under increasing $\mathrm{P}$ application rates. Therefore, in agricultural production, it is very important to avoid excessive use of $\mathrm{P}$ fertilizer, so that a balance is achieved between higher yield and appropriate grain Se concentration. Proper P management is crucial to grain Se concentration control. 
TABLE 2 | Research progress on the effects of nutrient elements on Se accumulation in higher plants.

\begin{tabular}{|c|c|c|c|c|c|}
\hline Added nutrition & Amounts & Crop species & Test results & Se availability & References \\
\hline $\mathrm{N}$ fertilizer & $0,20,40,80,120 \mathrm{~kg} \mathrm{ha}^{-1}$ & Rice & $\begin{array}{l}\text { The Se and protein content in rice grain increased with the increase of } \mathrm{N} \text { application, } \\
\text { and the grain Se content increased from } 0.03 \mathrm{mg} \mathrm{kg}^{-1} \text { to } 0.35 \mathrm{mg} \mathrm{kg}^{-1} \text {. }\end{array}$ & Increase & Reis et al., 2018 \\
\hline $\mathrm{N}$ fertilizer & $100,200 \mathrm{mg} \mathrm{kg}^{-1}$ & Wheat & $\begin{array}{l}\mathrm{N} \text { fertilizer increased the absorption of } \mathrm{Se}(\mathrm{VI}) \text { in wheat root and the migration of Se to } \\
\text { the aboveground. With the increase of } \mathrm{N} \text { fertilizer, the Se content in grain increased by } \\
22.6 \text { and } 12.1 \% \text {, respectively under the treatment of low and high Se. }\end{array}$ & Increase & Chen et al., 2017 \\
\hline$N$ fertilizer & $0,60 \mathrm{mg} \mathrm{kg}^{-1}$ & Wheat & $\mathrm{N}$ fertilizer increased the content of wheat grain Se. & - & Duncan et al., 2017 \\
\hline$N$ fertilizer & $0,40,80,120 \mathrm{~kg} \mathrm{ha}^{-1}$ & Wheat & $\begin{array}{l}\mathrm{N} \text { fertilizer increased wheat grain Se content by } 17.4,34.8 \text {, and } 82.6 \% \text { with the } \mathrm{N} \\
\text { content of } 40,80 \text {, and } 120 \mathrm{~kg} \mathrm{ha}^{-1} \text {, respectively. }\end{array}$ & - & Klikocka et al., 2017 \\
\hline P fertilizer & $0,1,2 \mathrm{~g} \mathrm{~kg}^{-1}$ & Wheat & $\begin{array}{l}\text { Under Se(IV) treatment, Se content and transfer factor of wheat decreased. P fertilizer } \\
\text { reduced the content of soluble and exchangeable Se in the soil and increased iron } \\
\text { oxide-bound Se or organic matter-bound Se. }\end{array}$ & Decrease & Zhang et al., 2017 \\
\hline P fertilizer & $0,1,2 \mathrm{~g} \mathrm{~kg}^{-1}$ & Wheat & $\begin{array}{l}\text { Under Se(VI) treatment, Se content and transfer factor of wheat increased. P fertilizer } \\
\text { significantly reduced the content of iron oxide-bound and organic matter-bound Se. }\end{array}$ & Increase & Zhang et al., 2017 \\
\hline P fertilizer & $0,80,160 \mathrm{mg} \mathrm{kg}^{-1}$ & Wheat & $\begin{array}{l}\text { In the presence of Se(IV), the } \mathrm{P} \text { fertilizer addition significantly reduced the concentration } \\
\text { of various forms of Se. }\end{array}$ & Decrease & Nie et al., 2020 \\
\hline $\begin{array}{l}\mathrm{NH}_{4} \mathrm{H}_{2} \mathrm{PO}_{4} \\
\left(\mathrm{NH}_{4}\right)_{2} \mathrm{HPO}_{4}\end{array}$ & $\begin{array}{l}1.96 \mathrm{~g} \mathrm{~kg}^{-1} \\
2.17 \mathrm{~g} \mathrm{~kg}^{-1}\end{array}$ & Wheat & $\begin{array}{l}\text { P fertilizer reduced the content of organic matter-bound and Fe and Mn oxide-bound } \\
\text { Se, and increased Se content in wheat }\end{array}$ & Increase & An et al., 2019 \\
\hline P fertilizer & $0,240 \mathrm{mg} \mathrm{kg}^{-1}$ & Rice & P fertilizer significantly reduced the Se concentrationin rice grain by $15.2 \%$. & Decrease & Shen, 2017 \\
\hline S fertilize & $0,20 \mathrm{mg} \mathrm{kg}^{-1}$ & Wheat & $S$ fertilizer decreased the content of wheat grain Se. & - & Duncan et al., 2017 \\
\hline S fertilize & $0,50 \mathrm{~kg} \mathrm{ha}^{-1}$ & Wheat & S fertilizer increased the content of wheat grain Se by $20.8 \%$. & - & Klikocka et al., 2017 \\
\hline S fertilize & $0,140 \mathrm{mg} \mathrm{kg}^{-1}$ & Rice & S fertilizer significantly reduced the Se concentrationin rice grain by $19.1 \%$. & Decrease & Shen, 2017 \\
\hline$S$ fertilize & $0,150,300 \mathrm{mg} \mathrm{kg}^{-1}$ & Rape & $\begin{array}{l}\text { S application reduced the Se content in rape and promoted the growth of rape. Sulfur } \\
\text { application only affected the Se absorption in root, but not the Se transportation. Sulfur } \\
\text { application significantly reduced rape seed Se content by } 28.2 \% \text { and } 40.4 \% \text { with the } \\
\text { sulfur content of } 150 \mathrm{mg} \mathrm{kg}^{-1} \text { and } 300 \mathrm{mg} \mathrm{kg}^{-1} \text { respectively. }\end{array}$ & Decrease & Liu et al., 2016b \\
\hline
\end{tabular}




\section{The Role of Sulfur in the Regulation of Se Bioavailability and Accumulation}

Sulfur and Se are elements of the same group in the periodic table, the "chalkogens." Therefore, $\mathrm{S}$ and Se have many chemical similarities. Studies have shown that plants absorb and assimilate Se and S using identical pathways (Table 2). Se(VI) as selenate is structurally similar to $\mathrm{SO}_{4}{ }^{2-}$, and $\mathrm{Se}(\mathrm{VI})$ is absorbed via $\mathrm{S}$ transporters resident in the root plasma membrane (Terry et al., 2000). S-fertilizer regimes in soils have potential significance in regulating Se bioavailability for many plant species (Duncan et al., 2017). The interaction between $S$ and Se in plants is complex (Table 2). Since the same transporters are shared when plants absorb $\mathrm{S}$ and $\mathrm{Se}(\mathrm{VI})$, there is often a competitive relationship in the absorption of $S$ and Se. The expression of sulfate transporters will vary depending on crop species and $S$ level. Hence, $\mathrm{S}$ fertilization can increase or decrease grain Se concentration, depending on crop species, crop $S$ status, and fertilizer regime/timing (Stroud et al., 2010).

For Se(IV), S fertilizers mostly produce competitive inhibition vis-a-vis the absorption of Se(IV). Mackowiak and Amacher (2008) showed that S fertilizer application reduced Se(IV) uptake by plants such as alfalfa and wheat grass. Dhillon and Dhillon (2000) reported that the application of $0.8 \mathrm{t} \mathrm{hm}^{-2}$ gypsum to selenite-rich soil significantly decreased total Se accumulation in rice, while increasing $S$ content, with minimal reductions in Se concentration in grains and straw by 35 and $36 \%$, respectively. S application can significantly inhibit Se(IV) absorption and accumulation (Lee et al., 2011; Liu et al., 2016a), but a hydroponic experiment also showed that selenite and sulfate had no antagonistic effects on Se uptake ( $\mathrm{Li}$ et al., 2008). This suggests that the inhibitory effect of $S$ fertilizer on Se(IV) uptake and accumulation by plants under soil cultivation depends on other processes rather than competitive adsorption. $S$ fertilizer application to the soil may change the physical and chemical behavior of Se(IV) in the soil. For example, $\mathrm{S}$ fertilizer significantly increases soil organic matter content, significantly decreases soil $\mathrm{pH}$, and increases microorganismal activity, which, in turn, may increase the amount of Se(IV) fixed in soil (Liu et al., 2015). Therefore, on Se-deficient soils with rich organic matter content and sufficient $S$, Se uptake by crops can be increased by reduced $\mathrm{S}$ fertilizer application. On the other hand, for Se-rich soils, organic matter deficiency, and insufficient $\mathrm{S}$, it is possible to reduce Se uptake by crops via increased S-fertilizer and organic-fertilizer application. S-fertilizer and organic-fertilizer management is therefore a critical determinant of Se accumulation in the crop.

\section{SE INTERACTION WITH HEAVY METALS (AS, HG, AND CD)}

\section{The Role of Selenium in the Regulation of Arsenic Bioavailability and Accumulation}

As is a highly toxic environmental pollutant, whose pollution is widespread throughout the world, including in many parts of United States, Europe, China, and Southeast Asia (Rahman et al., 2014). As and Se have a relatively close positioning in the periodic table of elements, and both are metalloids (even though As is often classified as a "heavy metal"), with similar chemical properties, and one can infer similar characteristics in plant absorption as well as in transport from the soil to plants. In recent years, in attempts to clarify the antagonistic effects Se and As have on one another, much insightful research has been produced. It is now clear that the antagonistic effects of As and Se on one another depend on the chemical forms of Se and As, the levels of Se and As in soil, and plant genotype (Table 3).

First, As(III) and Se(IV) enter the plant root system by sharing the same transporter, and there is competitive interaction between them at the influx level (Ma et al., 2008; Zhao X. et al., 2010; Li N. et al., 2016). That Se reduces As transport to the shoot has been confirmed in many studies (Chauhan et al., 2017; Camara et al., 2018). However, Bluemlein et al. (2009) reported that $\mathrm{As}(\mathrm{III})$ and $\mathrm{Se}(\mathrm{IV})$ have a synergistic effect in rice roots. This phenomenon has also been reported in other crops (Han et al., 2015). The exact mechanism is not clear, but this phenomenon is very interesting and needs further study.

The addition of Se significantly limits the transport of As from the root to the shoot. Hu et al. (2013) found that Se(IV) can significantly inhibit the transport of both $\mathrm{As}(\mathrm{III})$ and $\mathrm{As}(\mathrm{V})$ from root to shoot in rice. Zhou et al. (2017a) showed that Se can reduce the transport of As from soil to root, then from root to shoot and then to the grain in rice. Se restricts the transport of As for two main reasons: (1) As $(\mathrm{V})$ absorbed by plants is reduced to As(III) in root cells, and As(III) can be chelated in a Lewis acid-base reaction by reduced glutathione (GSH) or by phytochelatins (PCs) and finally stored in the root vacuole, thus curtailing As transport from root to shoot (Ye et al., 2011). Liao et al. (2016) showed that Se(IV) and Se(VI) application to the soil can reduce As concentration in the grains and husks. At the same time, Se(IV) was more effective than $\mathrm{Se}(\mathrm{VI})$ at reducing the grain As concentration in rice. (2) Se affects As transport direction at the stem node and transport in the phloem from leaves to grains. As is strongly accumulated in the vascular bundle stem node. The stem node is a central point of translocation from the xylem to the phloem, which plays a critical role in As distribution (Moore et al., 2014; Wan et al., 2018). The mechanism may be linked to enhanced development of apoplastic barriers (Casparian bands and suberin lamellae) in the endodermis by Se, which would limit the translocation of heavy metals into the xylem and then the shoots more broadly (Wang X. et al., 2014). This important connection of Se supplementation to barrier formation in roots and at the root-shoot interface requires further study, also with a view to water-use efficiency in plants (Plett et al., 2020).

Recently, several studies have addressed Se-mediated improvement of As toxicity from the perspective of genomics and proteomics. Transporters are the pivotal proteins that regulate As in above-ground parts of the plant. OsPTR7, a putative peptide transporter is involved in the long-distance translocation of DMA and contributes to the accumulation of DMA in rice grain (Tang et al., 2017). Inositol transporters (INTs) are responsible for As(III) loading into the phloem, the key source of arsenic in seeds (Duan et al., 2016). Se can 
TABLE 3 | Research progress on the effects of Se on accumulation of heavy metals in higher plants.

\begin{tabular}{|c|c|c|c|c|c|c|}
\hline Added Se form & Amounts & $\begin{array}{l}\text { Heavy metal } \\
\text { species }\end{array}$ & $\begin{array}{l}\text { Crop } \\
\text { species }\end{array}$ & Test results & $\begin{array}{l}\text { Heavy metal } \\
\text { availability }\end{array}$ & References \\
\hline Se(IV) & $0,0.5,1 \mathrm{mg} \mathrm{kg}^{-1}$ & As & Rice & $\begin{array}{l}\text { The addition of Se (IV) reduced total As content in soil solution, but increased } \\
\text { As content in rice grain by } 43.7-74.6 \% \text {. }\end{array}$ & Decrease & Wan et al., 2018 \\
\hline Se(IV) & $0,1,5,10 \mathrm{mg} \mathrm{kg}^{-1}$ & As & Rice & $\begin{array}{l}\text { Se (IV) application significantly reduced rice grain As content by } 8.6,31.4 \text {, and } \\
33.7 \% \text { with the Se content of } 1,5 \text {, and } 10 \mathrm{mg} \mathrm{kg}^{-1} \text {, respectively. }\end{array}$ & - & Zhou et al., 2017b \\
\hline $\mathrm{Se}(\mathrm{IV})$ & $0,1,5 \mathrm{mg} \mathrm{kg}^{-1}$ & As & Rice & $\begin{array}{l}\text { Se (IV) application reduced As availability in rhizosphere soil. Se (IV) application } \\
\text { significantly reduced the grain As content. }\end{array}$ & Decrease & Lv et al., 2020 \\
\hline $\mathrm{Se}(\mathrm{IV})$ & $0,0.5,3,6 \mathrm{mg} \mathrm{kg}^{-1}$ & $\mathrm{Hg}$ & Rice & $\begin{array}{l}\mathrm{Se}(\mathrm{IV}) \text { addition forms } \mathrm{IHg} \text {-Se complexes, resulting reduction of effectiveness of } \\
\mathrm{Hg} \text { in soil. As content in rice grain reduced with the increase of Se (IV) } \\
\text { concentration. }\end{array}$ & Decrease & Tang et al., 2017 \\
\hline $\mathrm{Se}(\mathrm{IV})$ & $0,20,40,60,100,300,500 \mathrm{mg} \mathrm{kg}^{-1}$ & $\mathrm{Hg}$ & Rice & $\begin{array}{l}\mathrm{Se}(\mathrm{IV}) \text { application decreased inorganic } \mathrm{Hg} \text { and } \mathrm{MeHg} \text { concentration in grain } \\
\text { and root. }\end{array}$ & Decrease & Xu et al., 2019 \\
\hline $\mathrm{Se}(\mathrm{IV})$ & $0,3 \mathrm{mg} \mathrm{kg}^{-1}$ & $\mathrm{Hg}$ & Rice & $\begin{array}{l}\text { Se(IV) application reduced MeHg content in soil and in rice root, straw and } \\
\text { grain. }\end{array}$ & Decrease & Wang et al., 2016 \\
\hline $\mathrm{Se}(\mathrm{IV})$ & $1 \mathrm{mg} \mathrm{kg}^{-1}$ & $\mathrm{Cd}$ & Rice & $\begin{array}{l}\text { Se(IV) reduced exchangeable } \mathrm{Cd} \text { content but increased the } \mathrm{Cd} \text { content } \\
\text { combined with carbonate and iron-manganese oxides. Se(IV) addition reduced } \\
\text { rice Cd content by } 36.5 \%\end{array}$ & Decrease & Huang et al., 2018 \\
\hline Se(IV) & $0,0.5,1,2,4,8 \mathrm{mg} \mathrm{kg}^{-1}$ & $\mathrm{Cd}$ & Wheat & Se(IV) reduced Cd content in wheat shoot from 25 to $35 \%$ & - & Atarodi et al., 2018 \\
\hline $\mathrm{Se}(\mathrm{IV})$ & $0,1,5,10,15,20 \mathrm{mg} \mathrm{kg}^{-1}$ & $\mathrm{Cd}$ & Rape & Se(IV) markedly reduced Cd concentration in both root and shoot. & - & Wu et al., 2016b \\
\hline Se(IV) & $0,1,5 \mathrm{mg} \mathrm{kg}^{-1}$ & $\mathrm{Cd}$ & Rice & $\begin{array}{l}\text { Se (IV) application reduced Cd availability in rhizosphere soil. Se (IV) application } \\
\text { significantly reduced the grain Cd content. }\end{array}$ & Decrease & Lv et al., 2020 \\
\hline $\mathrm{Se}(\mathrm{VI})$ & $0,0.1,1,5 \mathrm{mg} \mathrm{kg}^{-1}$ & As & Rice & Se(VI) addition reduced As content in rice root, shoot and grain. & - & Liao et al., 2016 \\
\hline $\mathrm{Se}(\mathrm{VI})$ & $0,0.5,3,6 \mathrm{mg} \mathrm{kg}^{-1}$ & $\mathrm{Hg}$ & Rice & $\begin{array}{l}\mathrm{Se}(\mathrm{VI}) \text { addition forms } \mathrm{Ig} \text {-Se complexes, resulting reduction of effectiveness of } \\
\mathrm{Hg} \text { in soil. } \mathrm{Hg} \text { content in rice grain reduced with the increase of } \mathrm{Se}(\mathrm{VI}) \\
\text { concentration. }\end{array}$ & Decrease & Tang et al., 2017 \\
\hline $\mathrm{Se}(\mathrm{VI})$ & $0,0.1,1,5 \mathrm{mg} \mathrm{kg}^{-1}$ & $\mathrm{Cd}$ & Rice & Se(VI) addition reduced Cd content in rice root, shoot and grain. & - & Liao et al., 2016 \\
\hline $\mathrm{Se}(\mathrm{VI})$ & $0,3 \mathrm{mg} \mathrm{kg}^{-1}$ & $\mathrm{Hg}$ & Rice & $\begin{array}{l}\text { Se(VI) application reduced MeHg content in soil and in rice root, straw and } \\
\text { grain. }\end{array}$ & Decrease & Wang et al., 2016 \\
\hline Undefined & $0,0.003,0.03,0.15,0.3,1.5 \mathrm{mg} \mathrm{kg}^{-1}$ & $\mathrm{Hg}$ & Rice & $\begin{array}{l}\text { Low Se concentration reduced } \mathrm{Hg} \text { and } \mathrm{MeHg} \text { content in rice grains, but high Se } \\
\text { concentration increased it. }\end{array}$ & - & Li et al., 2019a \\
\hline
\end{tabular}




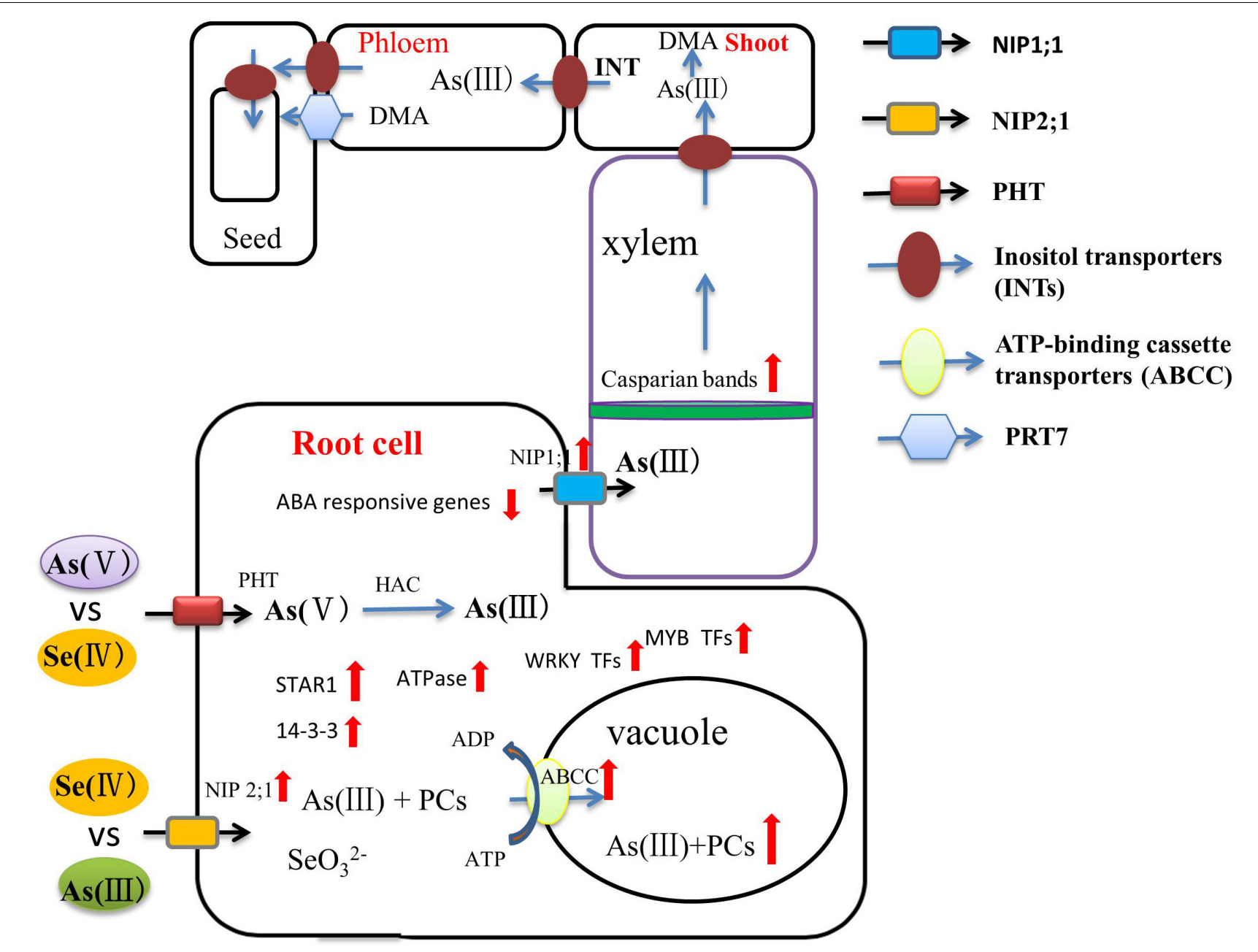

FIGURE 2 | A flow diagram of the role of Se in regulating As bioavailability and accumulation and transport through xylem and phloem to the grains. Inositol transporters (INTs) may be involved in the mobilization of As from source tissues to the phloem for subsequent transport to seed tissues. As(III) and Se(IV) enter the plant root system by sharing the NIP2;1 transporter. As $(\mathrm{V})$ and $\mathrm{Se}(\mathrm{IV})$ are absorbed by plant roots via phosphate transporters. ABC transporters can sequester As(III)-PCs complexes into vacuoles. Se significantly limits the transport of As from the root to the grain through enhanced development of apoplastic barriers and up-regulation of related genes (red arrow).

regulate the expression of these transporter proteins and, thus, directly affect As accumulation in the above-ground parts. Song et al. (2014) found that ABC transporters can sequester As(III)-PCs complexes into vacuoles in both Arabidopsis and rice. Chauhan et al. (2020) showed that the up-regulation of ABC transporters, ATPases, STAR1 protein, and 14-3-3 protein during $\mathrm{As}$ and $\mathrm{Se}$ co-exposure on both the transcriptome and proteome levels, some of which are also effective in limiting aluminum toxicity, indicating that Se can influence a reduction of As accumulation in rice by these means of facilitated vacuolar sequestration. The higher expression of regulation of WRKY, AUX/IAA, and MYB transcription factors that link to As tolerance and reduced expression of phosphate transporters, reducing As uptake, during As and Se co-exposure were also observed (Figure 2). However, detailed molecular analysis is needed to clarify the As/Se interactions in different plants further. This is of particular pressing important in rice, where As accumulation in the grain, in many common rice-cultivation areas, poses a significant health hazard to humans (Rahman and Hasegawa, 2011).

In the future, genomic and proteomic analyses will need to be combined to decipher with precision the molecular mechanisms by which Se reduces plant-shoot As accumulation, thus laying a foundation for comprehensively and thoroughly mapping out the molecular network of As regulation by Se.

\section{The Role of Selenium in the Regulation of Mercury Bioavailability and} Accumulation

Mercury $(\mathrm{Hg})$ is a global pollutant and carries significant toxicity to human health at very low concentration of exposure (Wang et al., 2016). Methyl mercury (MeHg) can be generated from inorganic $\mathrm{Hg}$ (IHg) by anaerobic microorganisms under flooded 


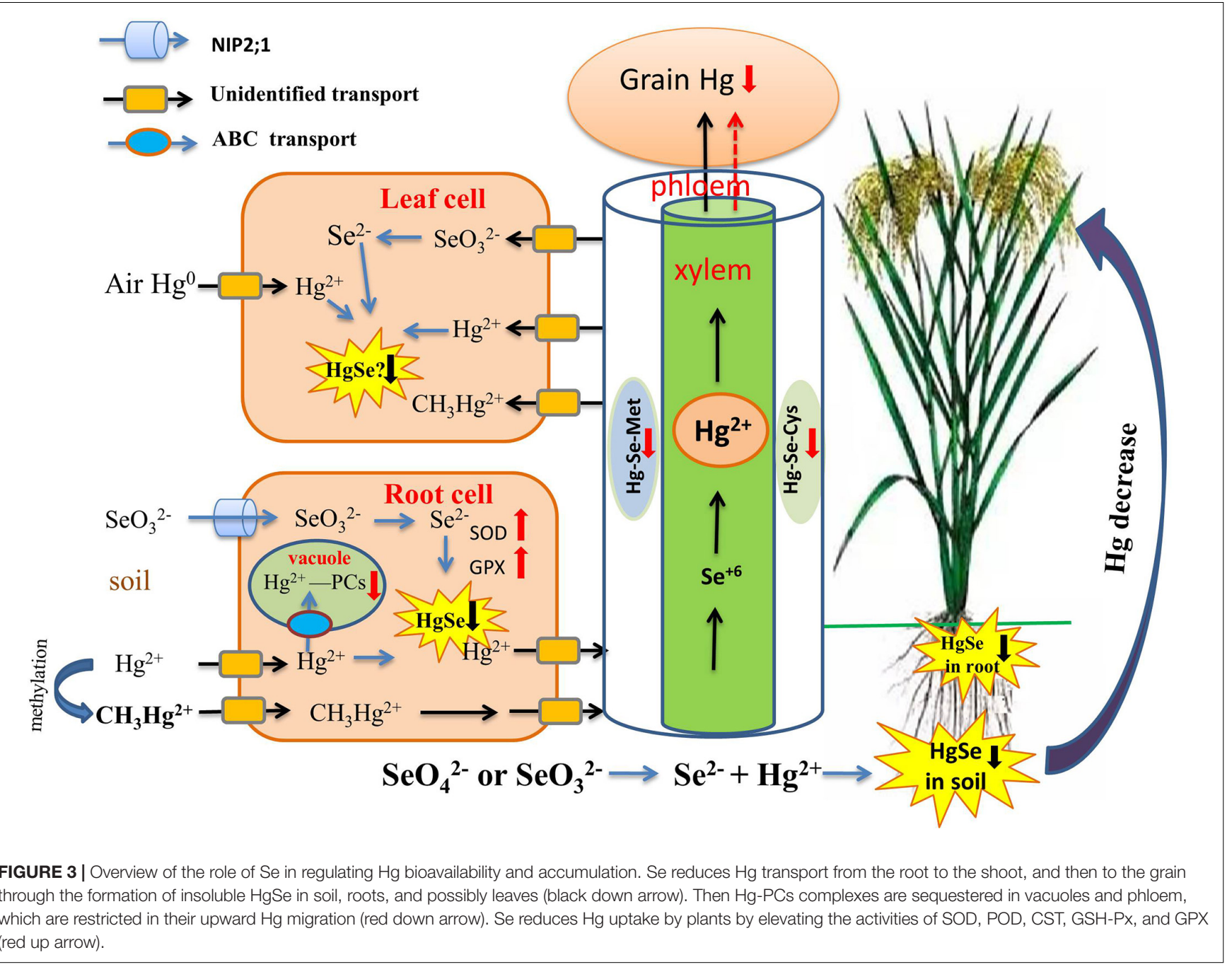

conditions. This form is then easily absorbed by plant roots, rapidly transported to edible plant parts, and, thereby, can directly threaten human health. Indeed, food consumption is the main source of $\mathrm{MeHg}$ exposure to humans (Zhang et al., 2010). As in the case of arsenic accumulation in the grain (see above), the problem of excessive concentration of $\mathrm{MeHg}$ in rice grains needs urgent attention. Soil $\mathrm{Hg}$ remediation technologies typically have the shortcomings of high cost and negative impact on the soil. However, recent studies have shown that Se can inhibit the transport and accumulation of $\mathrm{Hg}$ in plants, and this connection, therefore, must be understood (Table 3).

The antagonism of Se-Hg in the soil is a key process controlling $\mathrm{Hg}$ behavior in the soil-rice system (Figure 3). Recently, a series of studies by Wang X. et al. (2014); Wang et al. (2016) have provided a definitive explanation for the mechanism of antagonism of Se-Hg in soil. Se(IV) and $\mathrm{Se}(\mathrm{VI})$ were equally effective in reducing soil $\mathrm{MeHg}$ concentrations, possibly because of rapid changes in Se speciation and direct chemical reaction with Hg. Several recent experimental confirm the importance of the Se-Hg interaction in the soil Xu et al. (2019), at least for rice: (i) A direct chemical reaction between $\mathrm{Se}$ and $\mathrm{Hg}$ involves several steps and affects $\mathrm{Hg}$ bioavailability: Se(IV) and $\mathrm{Se}(\mathrm{VI})$ can be reduced to $\mathrm{Se}^{2-}$ and $\mathrm{Se}^{0}$ through microbial metabolism. $\mathrm{Se}^{2-}$ and $\mathrm{Hg}^{2+}$ then react directly and produce the insoluble compound $\mathrm{HgSe}$, thereby achieving sedimentation and inhibiting $\mathrm{Hg}$ methylation. The reaction formula is as follows:

$$
\mathrm{Hg}^{2+}+\mathrm{Se}^{2-}=\mathrm{HgSe} \text { or } \mathrm{Hg}^{0}+\mathrm{Se}^{0}=\mathrm{HgSe}
$$

Since the solubility constant for the reaction product $\left(10^{-58}\right), \mathrm{HgSe}$, is much smaller than that of $\mathrm{HgS}\left(10^{-52}\right)$, $\mathrm{Hg}^{2+}$ preferentially reacts with $\mathrm{Se}^{2-}$ ions to produce HgSe complex precipitate. Therefore, compared with $\mathrm{S}^{2-}$ $\left(\mathrm{HS}^{-}\right), \mathrm{Se}^{2-}\left(\mathrm{HSe}^{-}\right)$is more likely to react with $\mathrm{Hg}^{2+}$ and will form HgSe instead of HgS. TEM-EDX analysis results revealed that HgSe nanoparticles were formed in Seapplied soil in an anaerobic environment, which provided strong evidence for the direct Se-Hg interaction in soil (Wang et al., 2016). In addition, Chang et al. (2020) 
suggested that rice leaves can directly take up elemental $\mathrm{Hg}$ from the atmosphere, and Hg-Se complex may then be formed in rice leaves.

(ii) Co-exposure of $\mathrm{Hg}$ and $\mathrm{Se}$ can inhibit the growth of the sulfate-reducing bacterium D. desulfuricans when compared to Hg exposure alone (Truong et al., 2013), and this step is critical for the methylation of $\mathrm{IHg}$, leading to reduced production of $\mathrm{MeHg}$;

(iii) Se addition also increases demethylation and evaporation of $\mathrm{MeHg}$, resulting in decreased production of soil $\mathrm{MeHg}$ (Dang et al., 2019).

Se-Hg antagonism can also occur in dryland ecosystems, the mechanism for which is also that formation of insoluble HgSe complexes that precipitate and reduce $\mathrm{Hg}$ bioavailability and absorption by dryland plants. Tran et al. (2018a) demonstrated that the reduction in bioavailability of $\mathrm{Hg}$ depends on Se species; Se(IV) was more effective than $\mathrm{Se}(\mathrm{VI})$ in limiting $\mathrm{Hg}$ bioavailability and absorption, for pakchoi planted in dryland soil. It needs to be noted that such an effect only manifests significantly when $\mathrm{Se}(\mathrm{IV})$ and $\mathrm{Hg}$ are at a level of 2.5 and $3.0 \mathrm{mg}$ $\mathrm{kg}^{-1}$, respectively.

In addition to the formation of insoluble complexes, $\mathrm{Hg}$ Se antagonism also plays out on a different, plant-internal, level. The detoxification of $\mathrm{Hg}$, once absorbed, occurs by regulation of the metabolic production of antioxidant and chelation compounds in plants, which, in turn, presents an additional strategy for remediation of soil $\mathrm{Hg}$ and potentially reducing nutritional exposure to $\mathrm{Hg}$ if resultant compounds do not enter edible plant tissues. Tran et al. (2018b) showed that the Se application at 1.0 and $2.5 \mathrm{mg} / \mathrm{kg}$ led to significant reductions on $\mathrm{Hg}$ uptake by plants and increases in growth of pakchoi by elevating the activities of superoxide dismutase (SOD), peroxidase (POD), catalase (CST),glutathione peroxidase (GSH-Px) enzymes. In addition, Diao et al. (2014) found that Se could significantly increase GPX gene expression and enzyme activity. Third, Se can increase rice apoplastic barriers in the endodermis, which hinder both $\mathrm{IHg}$ and $\mathrm{MeHg}$ uptake (Zhou et al., 2014, 2017b; Wang X. et al., 2014). In addition, after Se treatment, there is less $\mathrm{Hg}$ in rice tissue due to the increased amount of iron plaque on the root surface, a natural barrier that prevents the accumulation of metal(loid)s in plants (Li Y. et al., 2016; Zhou and Li, 2019; Huang G. et al., 2020).

Selenium (Se) can also reduce $\mathrm{Hg}$ distribution in the embryo and endosperm of grains (Meng et al., 2014), which is very important for reducing the risk of human exposure to $\mathrm{Hg}$. Despite the recent significant research progress in the $\mathrm{Hg}$ Se interaction in plants, the mechanism by which Se reduces bioavailability of $\mathrm{Hg}$ in soil-plant systems has not yet been fully elucidated, and further research is needed to explore the effects of Se on Hg-methylated anaerobic microorganisms as well as the mechanism of Se-Hg antagonism. There is a need to conduct in-depth studies on the mechanism by which Se promotes $\mathrm{Hg}$ detoxification, both before it enters the plant and thereafter, and the mechanism by which Se prevents $\mathrm{Hg}$ entry into the grain, which carries important practical significance for effectively lowering the risk of human exposure to $\mathrm{Hg}$ while addressing the problem of insufficient dietary Se intake.

\section{The Role of Selenium in the Regulation of Cadmium Bioavailability and Accumulation}

$\mathrm{Cd}$ in the soil tends to accumulate in the roots of crops, followed by ready transport to edible parts and seriously affect human health (Hamid et al., 2019). Se application is considered as a potential solution to reduce $\mathrm{Cd}$ accumulation in plants. Indeed, the antagonism between Se and Cd has been studied in many different plants (Wan et al., 2016; Wu et al., 2016a; Affholder et al., 2019).

Antagonism between Se and Cd in the soil is complex and depends on factors such as Se and Cd dosage, applied Se species, and crop genotype (Table 3). Shanker et al. (1995) proposed that Se and Cd form CdSe complexes in soil unusable by plant roots. Huang et al. (2018) showed that Se can decrease total $\mathrm{Cd}$ concentration in soil solution by an average of $11.2-13.0 \%$, eventually affecting Cd uptake by plants. The mechanism has yet to be verified. Cd-Se antagonism also depends strongly on the prevailing Se species in soil solution. Liao et al. (2016) reported that Se(IV) can lower rice grain $\mathrm{Cd}$ concentration more effectively than $\mathrm{Se}(\mathrm{VI})$. This might be because $\mathrm{Se}(\mathrm{IV})$ has smaller mobility than $\mathrm{Se}(\mathrm{VI})$ in soil, leading to facilitated Cd-Se complexation and in reduced $\mathrm{Cd}$ absorption. Se-Cd antagonism also relates to Se and $\mathrm{Cd}$ dosage. Zhao et al. (2019) reported that, at $1 \mathrm{mmol} \mathrm{L}^{-1}$ $\mathrm{Cd}$, there was no significant difference in $\mathrm{Cd}$ concentration in the shoot and root of oilseed rape treated with Se at various levels; at $5 \mathrm{mmol} \mathrm{L}^{-1} \mathrm{Cd}$, however, Se addition (at 0.1 and $1 \mathrm{mmol} \mathrm{L}^{-1}$ ) significantly decreased root and shoot $\mathrm{Cd}$ concentration. Se addition (at $10 \mathrm{mmol} \mathrm{L}^{-1}$ ) significantly increased the concentration in both organs. It is possible that excessively high Se dosage damages rape seedlings (Saidi et al., 2014). Ding et al. (2014) reported that a high dose of Se increased the permeability of the root cells to $\mathrm{Cd}$, related to damage to the root cell membrane at elevated $\mathrm{Cd}$ concentrations. Hence, applying a well-adjudicated dose of Se, calibrated to the soil and crop system in question, is critical. By summarizing all the published studies on Se-Cd antagonism in plants to date Affholder et al. (2019) derived a quantitative model for predicting Se-Cd antagonism. Based on the model calculations, the authors concluded that, when the amount of Se applied to the root medium was $0.013,0.082$, and $142 \mathrm{mg}$ Se $\mathrm{kg}^{-1}$, crop Cd concentration was decreased by 10,25 , and $50 \%$, respectively.

Se-Cd antagonism not only occurs in soil, but also manifests inside plant cells. Huang et al. (2018) reported that Se application significantly reduced $\mathrm{Cd}$ concentration of different tissues and the translocation of $\mathrm{Cd}$ from roots to shoots in mature rice. However, Chang et al. (2013) reported that Se addition did not affect $\mathrm{Cd}$ concentration in rice roots, but reduced $\mathrm{Cd}$ accumulation in stems, leaves, rice husks, and grains. Pedrero et al. (2008) 


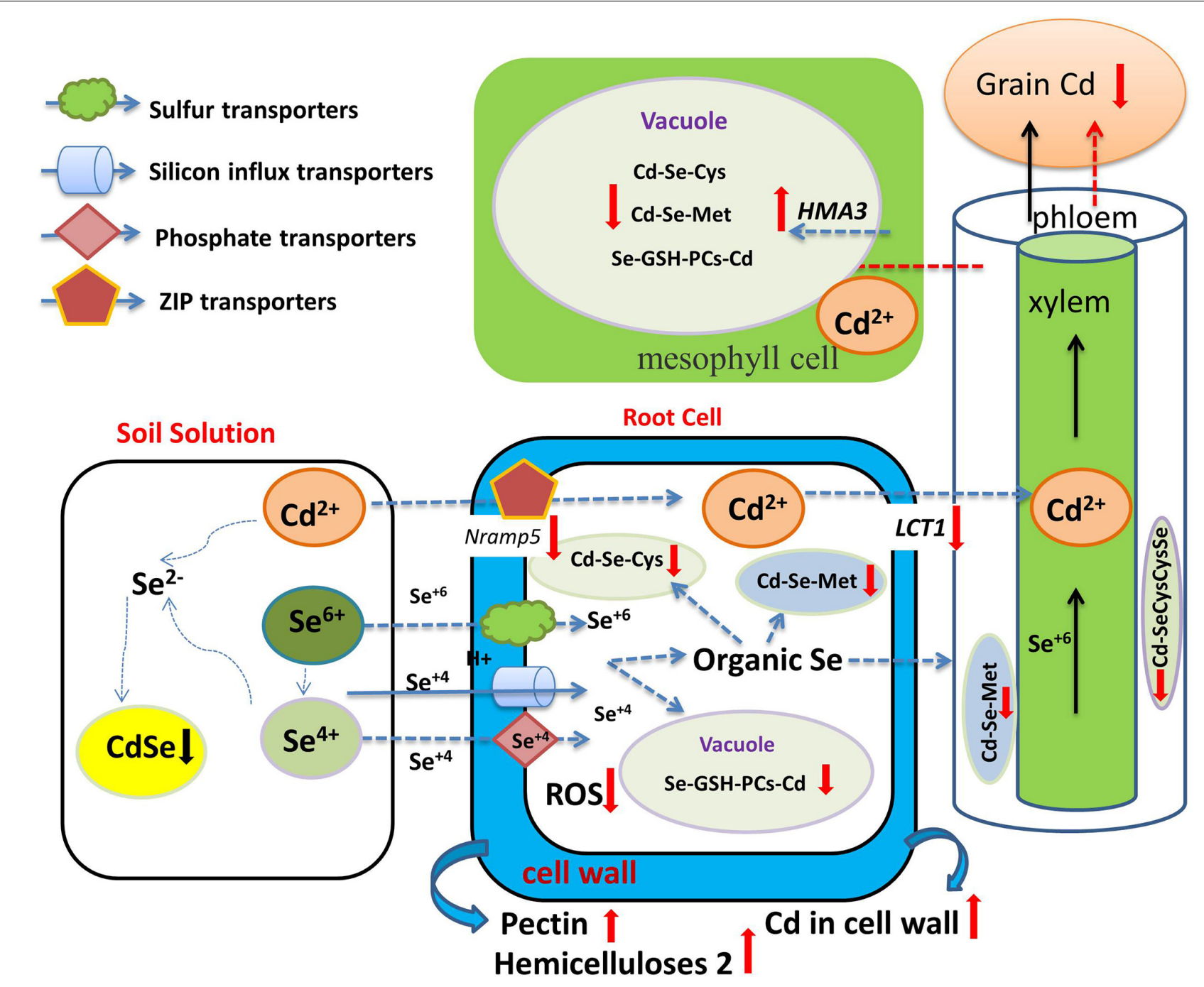

FIGURE 4 | Overview of the role of Se in regulating Cd bioavailability and accumulation. Se and Cd form CdSe complexes in soil unusable by plant roots (black down arrow). Se-Cd antagonism not only occurs in soil, but also manifests inside plant cells through the formation of Se- and Cd compounds, namely Cd-SeCysCysSe and Cd-SeMet (red down arrow), which are restricted in their upward, shoot-bound, Cd migration. Se reduces the expression of genes coding for Cd uptake and of transport-related genes (red down arrow), activates the expression of the tonoplast-resident transporter gene (red up arrow) and increases Cd accumulation in the plant cell wall (red up arrow). Se also increases GSH and PCs and reduces Cd transport from the root to the shoot and to the grain.

reported that Se addition decreased Cd concentration of the edible parts in broccoli, but increased $\mathrm{Cd}$ concentration in roots. These results indicate that the mechanism by which Se reduces the accumulation of $\mathrm{Cd}$ in aboveground tissue may be in the enhancement of root sequestration and the reduction of root-to-stem transport. Studies have shown that $\mathrm{Cd}$ and Se are absorbed by plant roots through different pathways or transporter proteins. Cd is absorbed by plant roots through zinc transfer proteins (ZIP) or cation channels (Lux et al., 2011), while Se is absorbed by plants through sulfate and phosphate transporters (Zhang L. et al., 2014, and see above). Se and Cd are absorbed by different transporters in the plant root system, so there is no direct competitive absorption relationship between Se and Cd. Recent years have witnessed great progress in our understanding of the mechanism of Se-Cd antagonism. Wu et al. (2016b) reported that Se application had no effect on Cd concentration or ratio in root saps, and Wan et al. (2016) showed that $\mathrm{Se}(\mathrm{IV})$ only played a minor role in $\mathrm{Cd}$ influx into rice roots, while $\mathrm{Se}(\mathrm{VI})$ had no effect at all. These results indicate that there is no competitive relationship in Se and $\mathrm{Cd}$ at the primary absorption level in plant roots. Se appears to only reduce $\mathrm{Cd}$ translocation from the root to the shoot, and a major component of this is the increase in GSH and PCs in the plant when Se supplementation is in play (see as well above). Cd is easily bound by S-containing ligands, such as those present in phytochelatins (PCs), metallothioneins, and glutathione (GSH) (Yadav, 2010). Yu et al. (2019) showed that the relative proportion of SeMet and $\mathrm{Se}(\mathrm{VI})$ was the main factor in the regulation of $\mathrm{Cd}$ accumulation in the plant. Zhang (2019) further showed that Se- and Cd-binding compounds, 
namely Cd-SeCysCysSe and Cd-SeMet, appeared in the stalk and leaf tissues after Se application in corn. These compounds are restricted in their upward, shoot-bound migration of Cd in plants (Figure 4).

One of the main effects of Cd toxicity is the inhibition of photosynthesis in higher plants (Wang Y. et al., 2014; Ahmad et al., 2016). Se application has been shown to reduce ethylene content, promote the accumulation of proline, and increase the activities of glutathione reductase (GR) and glutathione peroxidase (GPX) in wheat under Cd stress (Khan et al., 2015).

Zhao et al. (2019) found that Se increased the contents of pectin and hemicellulose 2. By combining with $\mathrm{Cd}$ ions, these compounds can limit $\mathrm{Cd}$ transport across cell plasma membranes, thereby reducing the entry of $\mathrm{Cd}$ into the roots and its transport to stems, pods, and seeds. Cui et al. (2018) reported that Se application reduced the expression of genes coding for $\mathrm{Cd}$ uptake (OsNramp5) and transport-related genes (OsLCT1), and reduced $\mathrm{Cd}$ uptake by rice cells, but activated the expression in the tonoplast transport gene OsHMA3 and lignin synthesis (OsPAL, OsCoMT Os4CL3)-related genes, making it more difficult for $\mathrm{Cd}$ to be transported from the vacuole to the phloem, and increasing $\mathrm{Cd}$ accumulation in the plant cell wall.

In summary, Se biofortification and reducing the risk of $\mathrm{Cd}$ pollution may have dual benefits. However, the results of the interactions between Se and Cd mainly depend on the rate of applications, plant species, and soil conditions (Feng et al., 2013; Wan et al., 2016). Under the context of high $\mathrm{Cd}$, Se-Cd interaction may be another case, and more studies are needed. Yang et al. (2019) concluded, based on field experiments, that high-Se soil did not reduce the absorption of $\mathrm{Cd}$ in rice, and high Se helped increase $\mathrm{Cd}$ translocation from root to stem. The reason may be that excessive $\mathrm{Cd}$ stress in this case may have caused serious damage to membranes and cell walls, chloroplasts, and other cell structures, resulting in decreased cellular integrity, photosynthetic rate, and plant growth. As well, Se application cannot reverse $\mathrm{Cd}$ damage to plant cells already incurred (Alves et al., 2020). Feng et al. (2013) found that $\mathrm{Se}$ increased the absorption of $\mathrm{Cd}$ and, when the $\mathrm{Cd}$ concentration was extremely high, deleterious effects on rice growth were readily evident. The authors linked this finding to cell membrane damage caused by Se application, increasing the permeability of root cells to Cd (Feng et al., 2017). This serves as an important warning that, in actual crop production settings, Cd reduction by Se application cannot automatically be assumed and requires more tests to determine precise application conditions, and blind implementation cannot be recommended.

\section{CONCLUSION AND FUTURE PERSPECTIVES}

In this review, we elucidate the nutritional effects of Se in plants and their consequences for crop consumption by humans, and summarize the basic mechanisms of uptake, long-distance transport, and biofortification of $\mathrm{Se}$ in grains. We further discuss Se biofortification and interaction mechanisms with the macronutrient elements $\mathrm{N}, \mathrm{P}$, and $\mathrm{S}$ and the heavy metals $\mathrm{Hg}$, As, and Cd. For human nutrition, any ideal crop must contain essential mineral elements such as Se, coupled to minimized accumulation of toxic elements in all edible parts, which are, typically, above-ground tissues. However, to achieve this goal, several hurdles need to be overcome:

(1) A comprehensive understanding of the uptake and transport systems for Se is required. Uptake and transport of Se from soils to edible plant parts is mediated by various transporters. However, we are far from fully understanding the molecular mechanisms of long-distance transport of Se to edible parts. Many transporters for Se remain to be identified. It is necessary to exploit the transporters regulating the primary absorption, internal transport, and accumulation of Se in plants, and transfer genes that code for them to relevant target plants to effect efficient expression, using transgenic technology or gene editing technology to increase the concentration of Se in non-Serich plants.

From the perspective of human nutrition and health, currently, it is urgent not only to increase the concentration of Se in the edible parts of crops, but also to increase some specific chemical Se forms, as different Se forms have varying nutritional value and toxicological properties in the human body. For instance, SeMeSeCys has promising anti-cancer properties, and overexpression of SeCys methyltransferase (SMT) may therefore present as the best choice for biofortification with a view to human nutrition. Applying modern techniques of molecular biology, targeted genes may also be overexpressed in specific plant tissues, such as in cereal reproductive structures, or in vegetative tissues of plants from which anticarcinogenic compounds can be easily extracted for large-scale production, such as in Medicago or in vegetable crops.

(2) It is important to further examine the effects of nutrient fertilizers ( $\mathrm{N}, \mathrm{P}, \mathrm{S}$, but also $\mathrm{K}$ and $\mathrm{Ca} / \mathrm{Mg}$ ) on plants in intensive agriculture production systems, especially vis-a-vis their effects on Se bioconcentration in grains, investigate the physiological and molecular mechanisms by which macronutrients affect long-distance transport of Se in crops, define agronomic production measures that simultaneously meet the high-yield nutritional needs of crops and nutritional balance requirements for Se, thus providing the theoretical and technical support needed for the genetic improvement of Se-rich crops and human health.

(3) The interaction mechanism between Se and heavy metals remains understudied. It is necessary to strengthen the research on the mechanisms by which Se may antagonize the toxicity of heavy metals, and study the effects of Se on the migration and transformation of heavy metals in soil-crop systems, especially the mechanisms by which 
Se restricts long-distance transport of heavy metals in cereal crops to the grain. It is urgent to conduct in-depth studies on the interactions between Se and heavy metals by using in-situ analytical techniques, such as synchrotron imaging. At the same time, a large number of field tests on different soil types are needed to clarify the effect of Se in improving Se nutrition level in crops and reducing heavy metal concentration in crops as well as refining the application conditions in a manner that might make them amenable to the application of precision agriculture techniques vis-a-vis Se. This will provide reference for using Se as a biostimulant to increase crop yields, improve crop nutritional value, and reduce the toxicities of soil metal toxicants.

\section{REFERENCES}

Affholder, M. C., Flöhr, A., and Kirchmann, H. (2019). Can Cd content in crops be controlled by Se fertilization? A meta-analysis and outline of Cd sequestration mechanisms. Plant Soil 440, 369-380. doi: 10.1007/s11104-01904078-x

Ahmad, P., Abd Allah, E. F., Hashem, A., Sarwat, M., and Gucel, S. (2016). Exogenous application of selenium mitigates cadmium toxicity in Brassica juncea L. (Czern \& Cross) by up-regulating antioxidative system and secondary metabolites. J. Plant Growth Regul. 35, 936-950. doi: 10.1007/s00344-0169592-3

Alves, L. R., Rossatto, D. R., Rossi, M. L., Martinelli, A. P., and Gratão, P. L. (2020). Selenium improves photosynthesis and induces ultrastructural changes but does not alleviate cadmium-stress damages in tomato plants. Protoplasma 257, 597-605. doi: 10.1007/s00709-019-01469-w

An, J., Zhang, D., Ye, J., Luo, D., and Wang, P. (2019). Influences of different phosphorus sources on selenium forms in soil and selenium absorption and transport in wheat (in Chinese). Jiangsu Agric. Sci. 47, 119-122. doi: 10.15889/j. issn.1002-1302.2019.16.026

Atarodi, B., Fotovat, A., Khorassani, R., Keshavarz, P., and Hammami, H. (2018). Interaction of selenium and cadmium in wheat at different salinities. Toxicol. Environ. Chem. 100, 348-360. doi: 10.1080/02772248.2018.152 4472

Bluemlein, K., Klimm, E., Raab, A., and Feldmann, J. (2009). Selenite enhances arsenate toxicity in Thunbergia alata. Environ. Chem. 6, 486-494. doi: 10.1071/ EN09101

Camara, A. Y., Wan, Y., Yu, Y., Wang, Q., and Li, H. (2018). Effect of selenium on uptake and translocation of arsenic in rice seedlings (Oryza sativa L.). Ecotox. Environ. Saf. 148, 869-875. doi: 10.1016/j.ecoenv.2017.11.064

Camara, A. Y., Wan, Y., Yu, Y., Wang, Q., Wang, K., and Li, H. (2019). Effect of endogenous selenium on arsenic uptake and antioxidative enzymes in Asexposed rice seedlings. Int. J. Environ. Res. Public Health 16:3350. doi: 10.3390/ ijerph16183350

Carey, A. M., Scheckel, K. G., Lombi, E., Newville, M., Choi, Y., Norton, G. J., et al. (2012). Grain accumulation of selenium species in rice (Oryza sativa L.). Environ. Sci. Technol. 46, 5557-5564. doi: 10.1021/es203871j

Chang, C., Chen, C., Yin, R., Shen, Y., Mao, K., Yang, Z., et al. (2020). Bioaccumulation of $\mathrm{Hg}$ in rice leaf facilitates selenium bioaccumulation in rice (Oryza sativa L.) Leaf in the Wanshan Mercury Mine. Environ. Sci. Technol. 54, 3228-3236. doi: 10.1021/acs.est.9b06486

Chang, H., Zhou, X., Wang, W., Zhou, Y., Dai, W., Zhang, C., et al. (2013). Effects of selenium application in soil on formation of iron plaque outside roots and cadmium uptake by rice plants. Adv. Mater. Res. 750, 1573-1576. doi: 10.4028/www.scientific.net/amr.750-752.1573

Chauhan, R., Awasthi, S., Indoliy, Y., Chauhan, A. S., Mishra, S., Agrawal, L., et al. (2020). Transcriptome and proteome analyses reveal selenium mediated amelioration of arsenic toxicity in rice (Oryza sativa L.). J. Hazard. Mater. 390:122122. doi: 10.1016/j.jhazmat.2020. 122122

\section{AUTHOR CONTRIBUTIONS}

$\mathrm{XZ}$ and JY wrote, drafted and checked the manuscript. WS designed and executed the manuscript. HK co-wrote the manuscript. All authors contributed to the article and approved the submitted version.

\section{FUNDING}

This research was supported financially by National Natural Science Foundation of China (Grant No. 31672238) and the Fundamental Research Funds for the Central Universities (Grant No. XDJK2019B039).

Chauhan, R., Awasthi, S., Srivastava, S., Dwivedi, S., Pilon-Smits, E. A. H., Dhankher, O. P., et al. (2019). Understanding seleni-um metabolism in plants and its role as a beneficial element. Crit. Rev. Environ. Sci. Technol. 49, 19371958. doi: 10.1080/10643389.2019.1598240

Chauhan, R., Awasthi, S., Tripathi, P., Mishra, S., Dwivedi, S., Niranjan, A., et al. (2017). Selenite modulates the level of phenolics and nutrient element to alleviate the toxicity of arsenite in rice (Oryza sativa L.). Ecotox. Environ. Saf. 138, 47-55. doi: 10.1016/j.ecoenv.2016.11.015

Chen, Q., Shi, W., and Wang, X. (2010). Selenium speciation and distribution characteristics in the rhizosphere soil of rice (Oryza sativa L.) seedlings. Commun. Soil Sci. Plant Anal. 41, 1411-1425. doi: 10.1080/00103624.2010. 482164

Chen, Y., Liang, D., Song, W., Lei, L., Yu, D., and Miao, S. (2016). Effects of nitrogen application on selenium accumulation, translocation and distribution of winter wheat at different growth periods (in Chinese). J. Plant Nutr. Fert. 22, 395-402. doi: 10.11674/zwyf.14349

Chen, Y., Liang, D., Song, W., Lei, L., Yu, D., and Miu, S. (2012). Effects of nitrogen application on selenium accumulation, translocation and distribution of winter wheat at different growth periods (in Chinese). J. Plant Nutr. Fert. 22, 395-402.

Chen, Y., Peng, Q., Liang, D., Song, W., Lei, L., and Yu, D. (2017). Effects of nitrogen application on selenium uptake, translocation and distribution in winter wheat (in Chinese). Environ. Sci. 38, 825-831. doi: 10.13227/j.hjkx. 201607194

Cui, J., Liu, T., Li, Y., and Li, F. (2018). Selenium reduces cadmium uptake into rice suspension cells by regulating the expression of lignin synthesis and cadmiumrelated genes. Sci. Total Environ. 644, 602-610. doi: 10.1016/j.scitotenv.2018. 07.002

Cui, Z., Chen, X., and Zhang, F. (2010). Current nitrogen management status and measures to improve the intensive wheat-maize system in China. AMBIO 39, 376-384. doi: 10.1007/s13280-010-0076-6

Dai, Z., Imtiaz, M., Rizwan, M., Yuan, Y., Huang, H., and Tu, S. (2019). Dynamics of selenium uptake, speciation, and antioxidant response in rice at different panicle initiation stages. Sci. Total Environ. 691, 827-834. doi: 10.1061/j. scitotenv.2019.07.186

D’Amato, R., Fontanella, M. C., Falcinelli, B., Beone, G. M., Bravi, E., Marconi, O., et al. (2018). Selenium biofortification in rice (Oryza sativa L.) sprouting: effects on Se yield and nutritional traits with focus on phenolic acid profile. J. Agric. Food Chem. 66, 4082-4090. doi: 10.1021/acs.jafc.8b 00127

Dang, F., Li, Z., and Zhong, H. (2019). Methylmercury and selenium interactions: mechanisms and implications for soil remediation. Crit. Rev. Environ. Sci. Technol. 3, 1737-1768. doi: 10.1080/10643389.2019.1583051

Dhillon, K. S., and Dhillon, S. K. (2000). Selenium accumulation by sequentially grown wheat and rice as influenced by gypsum application in a seleniferous soil. Plant Soil 227, 243-248. doi: 10.1023/a:1026579116794

Diao, M., Ma, L., Wang, J., Cui, J., Fu, A., and Liu, H.-Y. (2014). Selenium promotes the growth and photosynthesis of tomato seedlings under salt stress by enhancing chloroplast antioxidant defense system. J. Plant Growth Regul. 33, 671-682. doi: 10.1007/s00344-014-9416-2 
Ding, Y., Feng, R., Wang, R., Guo, J., and Zheng, X. (2014). A dual effect of Se on Cd toxicity: evidence from plant growth, root morphology and responses of the antioxidative systems of paddy rice. Plant Soil 375, 289-301. doi: 10.1007/ s11104-013-1966-8

Dinh, Q. T., Cui, Z., Huang, J., Tran, T. A. T., Wang, D., Yang, W., et al. (2018). Selenium distribution in the Chinese environment and its relationship with human health: a review. Environ. Int. 112, 294-309. doi: 10.1016/j.envint.2017. 12.035

Dinh, Q. T., Wang, M., Tran, T. A. T., Zhou, F., Wang, D., Zhai, H., et al. (2019). Bioavailability of selenium in soil-plant system and regulatory approach. Crit. Rev. Environ. Sci. Technol. 49, 443-517. doi: 10.1080/10643389.2018.1550987

Duan, G. L., Hu, Y., Schneider, S., McDermott, J., Chen, J., Sauer, N., et al. (2016). Inositol transporters atint 2 and atint 4 regulate arsenic accumulation in Arabidopsis seeds. Nat. Plants 2:15202. doi: 10.1038/nplants.2015.202

Duan, M., Cheng, S., Lu, R., Lai, R., Zhang, A., Ashraf, U., et al. (2019). Effect of foliar sodium selenate on leaf senescence of fragrant rice in south china. Appl. Ecol. Environ. Res. 17, 3343-3351. doi: 10.15666/aeer/1702_33433351

Duncan, E., Maher, W., Jagtap, R., Krikowa, F., Roper, M. M., and O’Sullivan, C. A. (2017). Selenium speciation in wheat grain varies in the presence of nitrogen and sulphur fertilisers. Environ. Geochem. Health 39, 955-966. doi: 10.1007/s10653-016-9857-6

Ei, K. E., Cathala, N., Rouached, H., Fourcroy, P., Berthomieu, P., Terry, N., et al. (2007). Characterization of a selenite-resistant Arabidopsis mutant. Root growth as a potential target for selenite toxicity. Plant Physiol. 143, 1231-1241. doi: 10.1104/pp.106.091462

Feng, R., Wei, C., Tu, S., Ding, Y., and Song, Z. (2013). A dual role of Se on $\mathrm{Cd}$ toxicity: evidences from the uptake of $\mathrm{Cd}$ and some essential elements and the growth responses in paddy rice. Biol. Trace Elem. Res. 151, 113-121. doi: 10.1007/s12011-012-9532-4

Feng, X., Han, L., Chao, D., Liu, Y., Zhang, Y., Wang, R., et al. (2017). Ionomic and transcriptomic analysis provides new insight into the distribu- tion and transport of cadmium and arsenic in rice. J. Hazard Mater. 331, 246-256. doi: 10.1016/j.jhazmat.2017.02.041

Gao, H., Chen, M., Hu, X., Chai, S., Qin, M., and Cao, Z. (2018). Separation of selenium species and their sensitive determination in rice samples by ionpairing reversed phase liquid chromatography with inductively coupled plasma tandem mass spectrometry. J. Sep. Sci. 41, 432-439. doi: 10.1002/jssc. 201700756

Guo, J. H., Liu, X. J., Zhang, Y., Shen, J. L., Han, W. X., Zhang, W. F., et al. (2010). Significant acidification in major Chinese croplands. Science 327, 1008-1010. doi: $10.1126 /$ science. 1182570

Gupta, M., and Gupta, S. (2017). An overview of selenium uptake, metabolism, and toxicity in plants. Front. Plant Sci. 7:2074. doi: 10.3389/fpls.2016.02074

Gupta, U. C., and Gupta, S. C. (2000). Selenium in soils and crops, its deficiencies in live stock and humans: implications for management. Commun. Soil Sci. Plant. 31, 1791-1807. doi: 10.1080/00103620009370538

Hamid, Y., Tang, L., Sohail, M. I., Cao, X., Hussain, B., Aziz, M. Z., et al. (2019). An explanation of soil amendments to reduce cadmium phytoavailability and transfer to food chain. Sci. Total Environ. 660, 80-96. doi: 10.1016/j.scitotenv. 2018.12.419

Han, D., Xiong, S., Tu, S., Liu, J., and Chen, C. (2015). Interactive effects of selenium and arsenic on growth, antioxidant system, arsenic and selenium species of Nicotiana tabacum L. Environ. Exp. Bot. 117, 12-19. doi: 10.1016/j.envexpbot. 2015.04.008

Harris, J., Schneberg, K. A., and Pilon-Smits, E. A. H. (2014). Sulfur-seleniummolybdenum interactions distinguish selenium hyperaccumulator Stanleya pinnata from non-hyperaccumulator Brassica juncea (Brassicaceae). Planta 239, 479-491. doi: 10.1007/s00425-013-1996-8

Hatfield, D. L., Tsuji, P. A., Carlson, B. A., and Gladyshev, V. N. (2014). Selenium and selenocysteine: roles in cancer, health, and development. Trends Biochem. Sci. 39, 112-120. doi: 10.1016/j.tibs.2013.12.007

Hu, Y., Huang, Y., and Liu, Y. (2013). Interactions between arsenic and selenium uptake and translocation in rice (Oryza sativa L.) seedlings (In Chinese). Environ. Chem. 32, 952-958. doi: 10.7524/j.issn.0254-6108.2013.06.005

Huang, G., Ding, C., Li, Y., Zhang, T., and Wang, X. (2020). Selenium enhances iron plaque formation by elevating the radial oxygen loss of roots to reduce cadmium accumulation in rice (Oryza sativa L.). J. Hazard Mater. 398:122860. doi: $10.1016 /$ j.jhazmat.2020.122860
Huang, S., Wang, P., Yamaji, N., and Ma, J.-F. (2020). Plant nutrition for human nutrition: hints from rice research and future perspectives. Mol. Plant 13, 825-835. doi: 10.1016/j.molp.2020.05.007

Huang, Q., Xu, Y., Liu, Y., Qin, X., Huang, R., and Liang, X. (2018). Selenium application alters soil cadmium bioavailability and reduces its accumulation in rice grown in Cd-contaminated soil. Environ. Sci. Pollut. Res. 25, 31175-31182. doi: 10.1007/s11356-018-3068-x

Jia, H., Song, Z., Wu, F., Ma, M., Li, Y., Han, D., et al. (2018). Low selenium increases the auxin concentration and enhances tolerance to low phosphorous stress in tobacco. Environ. Exp. Bot. 153, 127-134. doi: 10.1016/j.envexpbot. 2018.05.017

Khan, M. I. R., Nazir, F., Asgher, M., Per, T. S., and Khan, N. A. (2015). Selenium and sulfur influence ethylene formation and alleviate cadmiuminduced oxidative stress by improving proline and glutathione production in wheat. J. Plant Physiol. 173, 9-18. doi: 10.1016/j.jplph.2014.09.011

Kikkert, J., and Berkelaar, E. (2013). Plant uptake and translocation of inorganic and organic forms of selenium. Arch. Environ. Contam. Toxicol. 65, 458-465. doi: 10.1007/s00244-013-9926-0

Kim, H., Hirai, M. Y., Hayashi, H., Chino, M., Naito, S., and Fujiwara, T. (1999). Role of $\mathrm{O}$-acetyl-L-serine in the coordinated regulation of the expression of a soybean seed storage-protein gene by sulfur and nitrogen nutrition. Planta 209, 282-289. doi: 10.1007/s004250050634

Klikocka, H., Szostak, B., Barczak, B., and Kobialka, A. (2017). Effect of sulphur and nitrogen fertilization on the selenium content and uptake by grain of spring wheat. J. Elem. 22, 985-994. doi: 10.5601/jelem.2016.21.3.1296

Lee, S., Woodard, H. J., and Doolittle, J. J. (2011). Effect of phosphate and sulfate fertilizers on selenium uptake by wheat (Triticum aestivum). Soil Sci. Plant Nutri. 57, 696-704. doi: 10.1080/00380768.2011.623282

Liang, Y. K., Su, Y., Li, L., Huang, X., Panhwar, F. H., Zheng, T. D., et al. (2019). Quick selenium accumulation in the selenium-rich rice and its physiological responses in changing selenium environments. BMC Plant Biol. 19:559. doi: 10.1186/s12870-019-2163-6

Li, H.-F., McGrath, S. P., and Zhao, F.-J. (2008). Selenium uptake, translocation and speciation in wheat supplied with selenate or selenite. New Phytol. 178, 92-102. doi: 10.1111/j.1469-8137.2007.02343.x

Li, N., Wang, J., and Song, W. (2016). Arsenic uptake and translocation in plants. Plant Cell Physiol. 57, 4-13. doi: 10.1093/pcp/pcv143

Li, Y., Zhao, J., Zhang, B., Liu, Y., Xu, X., Li, Y.-F., et al. (2016). The influence of iron plaque on the absorption, translocation and transformation of mercury in rice (Oryza sativa L.) seedlings exposed to different mercury species. Plant Soil 398, 87-97. doi: 10.1007/s11104-0152627-x

Li, S., Bañuelos, G. S., Min, J., and Shi, W. (2015). Effect of continuous applicaition of inorganic nitrogen fertilizer on selenium concentration in vegetable grown in the Taihu Lake region of China. Plant Soil 393, 351-360. doi: 10.1007/s11104015-2496-3

Li, S., Bañuelos, G. S., Wu, L., and Shi, W. (2014). The changing selenium nutritional status of Chinese residents. Nutrients 6, 1103-1114. doi: 10.3390/ nu6031103

Li, Y., Hu, W., Zhao, J., Chen, Q., Wang, W., Li, B., et al. (2019a). Selenium decreases methylmercury and increases nutritional elements in rice growing in mercury contaminated farmland. Ecotox. Environ. Saf. 182:109447. doi: 10. 1016/j.ecoenv.2019.109447

Li, Y., Yu, S., and Zhou, X. (2019b). Effects of phosphorus on absorption and transport of selenium in rice seedlings. Environ. Sci. Pollut. Res. 26, 1375513761. doi: 10.1007/s11356-018-2690-y

Liao, G., Xu, Y., Chen, C., Wu, Q., Feng, R., Guo, J., et al. (2016). Root application of selenite can simultaneously reduce arsenic and cadmium accumulation and maintain grain yields, but show negative effects on the grain quality of paddy soil. J. Environ. Manag. 183, 733-741. doi: 10.1016/j.jenvman.2016. 09.031

Lima, L. W., Pilon-Smits, E. A. H., and Schiavon, M. (2018). Mechanisms of selenium hyperaccumulation in plants: a survey of molecular, biochemical and ecological cues. Biochim. Biophys. Acta Gen. Subj. 18:30090. doi: 10.1016/j. bbagen.2018.03.028

Liu, H., Shi, Z., Li, J., Zhao, P., Qin, S., and Nie, Z. (2018). The impact of phosphorus supply on Se uptake during hydroponics experiment of winter wheat 
(Triticum aestivum) in China. Front. Plant Sci. 9:373. doi: 10.3389/fpls.2018. 00373

Liu, X., Wang, Q., Hu, C., Zhao, X., Duan, B., and Zhao, Z. (2016a). Regulatory effects of sulfur on oilseed rape (Brassica napus L.) response to selenite. Soil Sci. Plant Nutr. 62, 247-253. doi: 10.1080/00380768.2016.1172023

Liu, X., Zhao, Z., Hu, C., Zhao, X., and Guo, Z. (2016b). Effect of sulphate on selenium uptake and translocation in rape (Brassica napus L.) supplied with selenate or selenite. Plant Soil 399, 295-304. doi: 10.1007/s11104-015-2699-7

Liu, X., Zhao, Z., Duan, B., Hu, C., Zhao, X., and Guo, Z. (2015). Effect of applied sulphur on the uptake by wheat of selenium applied as selenite. Plant Soil 386, 35-45. doi: 10.1007/s11104-014-2229-z

Lux, A., Martinka, M., Vaculiik, M., and White, P. J. (2011). Root responses to cadmium in the rhizosphere: a review. J. Exp. Bot. 62, 21-37. doi: 10.1093/jxb/ erq281

Lv, H., Chen, W., Zhu, Y., Yang, J., Mazharm, S., Zhao, P., et al. (2020). Efficiency and risks of selenite combined with different water conditions in reducing uptake of arsenic and cadmium in paddy rice. Environ. Pollut. 262:114283. doi: 10.1016/j.envpol.2020.114283

Ma, J. F., Yamaji, N., Mitani, N., Xu, X.-Y., Su, Y.-H., McGrath, S. P., et al. (2008). Transporters of arsenite in rice and their role in arsenic accumulation in rice grain. Proc. Natl. Acad. Sci. U.S.A. 105, 9931-9935. doi: 10.1073/pnas. 0802361105

Mackowiak, C. L., and Amacher, M. C. (2008). Soil sulfur amendments suppress selenium uptake by alfalfa and western wheatgrass. J. Environ. Qual. 37, 772779. doi: $10.2134 /$ jeq 2007.0157

Meng, B., Feng, X., Qiu, G., Anderson, C. W. N., Wang, J., and Zhao, L. (2014). Localization and speciation of mercury in brown rice with implications for pan-Asian public health. Environ. Sci. Technol. 48, 7974-7981. doi: 10.1021/ es502000d

Moore, K. L., Chen, Y., van de Meene, A. M. L., Hughes, L., Liu, W., Geraki, T., et al. (2014). Combined Nano SIMS and synchrotron X-ray fluorescence reveal distinct cellular and subcellular distribution patterns of trace elements in rice tissues. New Phytol. 201, 104-115. doi: 10.1111/nph.12497

Morlon, H., Fortin, C., Adam, C., and Garnier-Laplace, J. (2006). Selenite transport and its inhibition in the unlicellular green alga Chlamydomonas reinhardtii. Environ. Toxicol. Chem. 25, 1408-1417. doi: 10.1897/2512039.1

Natasha, S. M., Niazi, N. K., Khalid, S., Murtaza, B., and Bibi, I. (2018). A critical review of selenium biogeochemical behavior in soil-plant system with an inference to human health. Environ. Pollut. 234, 915-934. doi: 10.1016/j.envpol. 2017.12.019

Newman, R., Waterland, N., Moon, Y., and Tou, J. C. (2019). Selenium biofortification of agricultural crops and effects on plant nutrients and bioactive compounds important for human health and disease prevention-a review. Plant Food Hum. Nutr. 74, 449-460. doi: 10.1007/s11130-019-00769-Z

Nie, Z., Zhu, J., Li, J., Liu, H., Zhao, P., Zhao, P., et al. (2020). Phosphorus application alters concentrations and proportions of organic Se forms in the grain of winter wheat. J. Plant Nutri. Soil Sci. 183, 282-291. doi: 10.1002/jpln. 201900045

Pedrero, Z., Madrid, Y., Hartikainen, H., and Cámara, C. (2008). Protective effect of selenium in broccoli (Brassica oleracea) plants subjected to cadmium exposure. J. Agric. Food Chem. 56, 266-271. doi: 10.1021/jf072266w

Pilon-Smits, E. A. H., Winkel, L. H. E., and Lin, Z. (2017). Selenium in Plants: Molecular, Physiological, Ecological and Evolutionary Aspects. Cham: Springer.

Plett, D. C., Ranathunge, K., Melino, V. J., Kuya, N., Uga, Y., and Kronzucker, H. J. (2020). The intersection of nitrogen nutrition and water use in plants: new paths toward improved crop productivity. J. Exp. Bot. 71, 4452-4468. doi: $10.1093 / \mathrm{jxb} / \mathrm{eraa} 049$

Poblaciones, M. J., Rodrigo, S., Santamaría, O., Chen, Y., and McGrath, S. P. (2014). Agronomic selenium biofortification in Triticum durum under Mediterranean conditions: from grain to cooked pasta. Food Chem. 146, 378-384. doi: 10.1016/ j.foodchem.2013.09.070

Rahman, M. A., and Hasegawa, H. (2011). High levels of inorganic arsenic in rice in areas where arsenic-contaminated water is used for irrigation and cooking. Sci. Total Environ. 409, 4645-4655. doi: 10.1016/j.scitotenv.2011.07.068

Rahman, S., Kim, K.-H., Saha, S. K., Swaraz, A. M., and Paul, D. K. (2014). Review of remediation techniques for arsenic (As) contamination: a novel approach utilizing bio-organisms. J. Environ. Manag. 134, 175-185. doi: 10. 1016/j.jenvman.2013.12.027
Reis, H. P. G., Barcelos, J. P. D., Furlani Junior, E., Santos, E. F., Silva, V. M., Moraes, M. F., et al. (2018). Agronomic biofortification of upland rice with selenium and nitrogen and its relation to grain quality. J. Cereal Sci. 79, 508-515. doi: 10.1016/j.jcs.2018.01.004

Renkema, H., Koopmans, A., Kersbergen, L., Kikkert, J., Hale, B., and Berkelaar, E. (2012). The effect of transpiration on selenium uptake and mobility in durum wheat and spring canola. Plant Soil 354, 239-250. doi: 10.1007/s11104-0111069-3

Roman, M., Jitaru, P., and Barbante, C. (2014). Selenium biochemistry and its role for human health. Metallomics 6, 25-54. doi: 10.1039/C3MT00185G

Saidi, I., Chtourou, Y., and Djebali, W. (2014). Selenium alleviates cadmium toxicity by preventing oxidative stress in sunflower (Helianthus annuus) seedlings. J. Plant Physiol. 171, 85-91. doi: 10.1016/j.jplph.2013.09.024

Schiavon, M., Nardi, S., dalla Vecchia, F., and Ertani, A. (2020). Selenium biofortification in the 21st century: status and challenges for healthy human nutrition. Plant Soil 453, 245-270. doi: 10.1007/s11104-020-04635-9

Schiavon, M., Pilon, M., Malagoli, M., and Pilon-Smits, E. A. H. (2015). Exploring the importance of sulfate transporters and ATP sulphurylases for selenium hyperaccumulation-a comparison of Stanleya pinnata and Brassica juncea (Brassicaceae). Front. Plant Sci. 6:2. doi: 10.3389/fpls.2015.00002

Schiavon, M., and Pilon-Smits, E. A. H. (2017). Selenium biofortification and phytoremediation phytotechnologies: a review. J. Environ. Qual. 46, 10-19. doi: $10.2134 /$ jeq2016.09.0342

Shanker, K., Mishra, S., Srivastava, S., Srivastava, R., Dass, S., Prakash, S., et al. (1995). Effect of selenite and selenate on plant uptake of cadmium by kidney bean (Phaseolus mungo) with reference to Cd-Se interaction. Chem. Spec. Bioavailab. 7, 97-100. doi: 10.1080/09542299.1995.11083251

Shen, F. K. (2017). Soil Factors, Sulfur and Phosphorus Fertilizations Affecting Selenium Accumulation in Paddy Rice (Oryza sativa L.). Master's thesis, Guangxi University, Guangxi.

Song, W. Y., Yamaki, T., Yamaji, N., Ko, D., Jung, K. H., Fujii-Kashino, M., et al. (2014). A rice ABC transporter, OsABCC1, reduces arsenic accumulation in the grain. Proc. Natl. Acad. Sci. U.S.A. 111, 15699-15704. doi: 10.1073/pnas. 1414968111

Song, Z., Shao, H., Huang, H., Shen, Y., Wang, L., Wu, F., et al. (2017). Overexpression of the phosphate transporter gene OsPT8 improves the Pi and selenium contents in Nicotiana tabacum. Environ. Exp. Bot. 137, 158-165. doi: 10.1016/j.envexpbot.2017.02.011

Sors, T. G., Ellis, D. R., Na, G. N., Lahner, B., Lee, S., Leustek, T., et al. (2005). Analysis of sulfur and selenium assimilation in Astragalus plants with varying capacities to accumulate selenium. Plant J. Cell Mol. Biol. 42, 785-797. doi: 10.1111/j.1365-313X.2005.02413.x

Stroud, J. L., Li, H., Lopez-Bellido, F. J., Broadley, M. R., Foot, I., Fairweather-Tait, S. J., et al. (2010). Impact of sulphur fertilisation on crop response to selenium fertilisation. Plant Soil 332, 31-40. doi: 10.1007/s11104-009-0230-8

Sun, G.-X., Liu, X., Williams, P. N., and Zhu, Y.-G. (2010). Distribution and translocation of selenium from soil to grain and its speciation in paddy rice (Oryza sativa L.). Environ. Sci. Technol. 44, 6706-6711. doi: 10.1021/es101843x

Szlachta, M., Gerda, V., and Chubar, N. (2012). Adsorption of arsenite and selenite using an inorganic ion exchanger based on $\mathrm{Fe}-\mathrm{Mn}$ hydrous oxide. J. Colloid Interf. Sci. 365, 213-221. doi: 10.1016/j.jcis.2011. 09.023

Tan, L. C., Nancharaiah, Y. V., van Hullebusch, E. D., and Lens, P. N. L. (2016). Selenium: environmental significance, pollution, and biological treatment technologies. Biotechnol. Adv. 34, 886-907. doi: 10.1016/j.biotechadv.2016.05. 005

Tang, W., Dang, F., Evans, D., Zhong, H., and Xiao, L. (2017). Understanding reduced inorganic mercury accumulation in rice following selenium application: selenium application routes, speciation and doses. Chemosphere 169, 369-376. doi: 10.1016/j.chemosphere.2016.11.087

Terry, N., Zayed, A. M., de Souza, M. P., and Tarun, A. S. (2000). Selenium in higher plants. Annu. Rev. Plant Biol. 51, 401-432. doi: 10.1146/annurev.arplant.51.1. 401

Tran, T. A. T., Dinh, Q. T., Cui, Z., Huang, J., Wang, D., Wei, T., et al. (2018a). Comparing the influence of selenite (Se4+) and selenate (Se6+) on the inhibition of the mercury ( $\mathrm{Hg}$ ) phytotoxicity to pak choi. Ecotox. Environ. Saf. 147, 897-904. doi: 10.1016/j.ecoenv.2017. 09.061 
Tran, T. A. T., Zhou, F., Yang, W., Wang, M., Dinh, Q. T., Wang, D., et al. (2018b). Detoxification of mercury in soil by selenite and related mechanisms. Ecotoxicol. Environ. Saf. 159, 77-84. doi: 10.1016/j.ecoenv.2018.04.029

Truong, H. Y. T., Chen, Y.-W., and Belzile, N. (2013). Effect of sulfide, selenite and mercuric mercury on the growth and methylation capacity of the sulfate reducing bacterium Desulfovibrio desulfuricans. Sci. Total Environ. 449, 373384. doi: 10.1016/j.scitotenv.2013.01.054

Ulhassan, Z., Gill, R. A., Ali, S., Mwamba, T. M., Ali, B., Wang, J., et al. (2019). Dual behavior of selenium: insights into physio-biochemical, anatomical and molecular analyses of four Brassica napus cultivars. Chemosphere 225, 329-341. doi: 10.1016/j.chemosphere.2019.03.028

Ullah, H., Liu, G. J., Yousaf, B., Ali, M. U., Irshad, S., Abbas, Q., et al. (2019). A comprehensive review on environmental transformation of selenium: recent advances and research perspectives. Environ. Geochem. Health 41, 1003-1035. doi: 10.1007/s10653-018-0195-8

Wan, Y., Camara, A. Y., Huang, Q., Yu, Y., Wang, Q., and Li, H. (2018). Arsenic uptake and accumulation in rice (Oryza sativa L.) with selenite fertilization and water managemant. Ecotoxicol. Environ. Saf. 156, 67-74. doi: 10.1016/j.ecoenv. 2018.02.074

Wan, Y., Yu, Y., Wang, Q., Qiao, Y., and Li, H. (2016). Cadmium uptake dynamics and translocation in rice seedling: influence of different forms of selenium. Ecotox. Environ. Saf. 133, 127-134. doi: 10.1016/j.ecoenv.2016.07.001

Wang, J., Cappa, J. J., Harris, J. P., Edger, P. P., Zhou, W., Pires, J. C., et al. (2018). Transcriptome-wide comparison of selenium hyperaccumulator and non-accumulator Stanleya species provides new insight into key processes mediating the hyperaccumulation syndrome. Plant Biotechnol. J. 16, 15821594. doi: $10.1111 /$ pbi. 12897

Wang, X., Tam, N. F.-Y., Fu, S., Ametkhan, A., Ouyang, Y., and Ye, Z. (2014). Selenium addition alters mercury uptake, bioavailability in the rhizosphere and root anatomy of rice (Oryza sativa). Ann. Bot. 114, 271-278. doi: 10.1093/aob/ mcul17

Wang, Y., Jiang, X., Li, K., Wu, M., Zhang, R., Zhang, L., et al. (2014). Photosynthetic responses of Oryza sativa L. seedlings to cadmium stress: physiological, biochemical and ultrastructural analyses. Biometals 27, 389-401. doi: 10.1007/s10534-014-9720-0

Wang, Y., Dang, F., Evans, R. D., Zhong, H., Zhao, J., and Zhou, D. (2016). Mechanistic understanding of MeHg-Se antagonism in soil-rice systems: the key role of antagonism in soil. Sci. Rep. 6:19477. doi: 10.1038/srep19477

White, P. J. (2016). Selenium accumulation by plants. Ann. Bot. 227, 217-235. doi: $10.1093 / \mathrm{aob} / \mathrm{mcv} 180$

White, P. J. (2018). Selenium metabolism in plant. Biochim. Biophys. Acta Gen. Subj. 1862, 2333-2342. doi: 10.1016/j.bbagen.2018.05.006

White, P. J., and Broadley, M. R. (2009). Biofortification of crops with seven mineral elements often lacking in human diets - iron, zinc, copper, calcium, magnesium, selenium and iodine. New Phytol. 182, 49-84. doi: 10.1111/j.14698137.2008.02738.x

Williams, P. N., Lombi, E., Sun, G.-X., Scheckel, K., Zhu, Y.-G., Feng, X., et al. (2009). Selenium characterization in the global rice supply chain. Environ. Sci. Technol. 43, 6024-6030. doi: 10.1021/es900671m

Winkel, L. H. E., Vriens, B., Jones, G. D., Schneider, L. S., Pilon-Smits, E., and Bañuelos, G. S. (2015). Selenium cycling across soil-plant-atmosphere interfaces: a critical review. Nutrients 7, 4199-4239. doi: 10.3390/nu7064199

Wu, Z., Bañuelos, G. S., Lin, Z.-Q., Liu, Y., Yuan, L., Yin, X., et al. (2015). Biofortification and phytoremediation of selenium in China. Front. Plant Sci. 6:136. doi: 10.3389/fpls.2015.00136

Wu, Z., Wang, F., Liu, S., Du, Y., Li, F., Du, R., et al. (2016a). Comparative responses to silicon and selenium in relation to cadmium uptake, compartmentation in roots, and xylem transport in flowering Chinese cabbage (Brassica campestris L. ssp. chinensis var. utilis) under cadmium stress. Environ. Exp. Bot. 131, 173-180. doi: 10.1016/j.envexpbot.2016.07.012

Wu, Z., Yin, X., Banuelos, G., Lin, Z., Liu, Y., Li, M., et al. (2016b). Indications of selenium protection against cadmium and lead toxicity in oilseed rape (Brassica napus L.). Front. Plant Sci. 7:1875. doi: 10.3389/fpls.2016.01875

Xu, W. F., Chen, Q. X., and Shi, W. M. (2010). Effects of nitrate supply site on selenite uptake by rice roots. J. Agric. Food Chem. 58, 11075-11080. doi: 10.1021/jf102263e

Xu, X., Yan, M., Liang, L., Lu, Q., Han, J., Liu, L., et al. (2019). Impacts of selenium supplementation on soil mercury speciation, and inorganic mercury and methylmercury uptake in rice (Oryza sativa L.). Environ. Pollut. 249, 647-654. doi: 10.1016/j.envpol.2019.03.095

Yadav, S. K. (2010). Heavy metals toxicity in plants: an overview on the role of glutathione and phytochelatins in heavy metal stress tolerance of plants. S. Afr. J. Bot. 76, 167-179. doi: 10.1016/j.sajb.2009.10.007

Yang, B. B., Yang, C., Shao, Z.-Y., Wang, H., Zan, S.-T., Zhu, M., et al. (2019). Selenium (Se) does not reduce cadmium (Cd) uptake and translocation in rice (Oryza sativa L.) in naturally occurred Se-rich paddy fields with a high geological background of Cd. Bull. Environ. Contam. Toxicol. 103, 127-132. doi: 10.1007/s00128-019-02551-y

Ye, W.-L., Khan, M. A., McGrath, S. P., and Zhao, F.-J. (2011). Phytoremediation of arsenic contaminated paddy soils with Pteris vittata markedly reduces arsenic uptake by rice. Environ. Pollut. 159, 3739-3743. doi: 10.1016/j.envpol.2011.07. 024

Yu, Y., Zhuang, Z., Luo, L.-Y., Wang, Y.-Q., and Li, H.-F. (2019). Difference between selenite and selenate in selenium transformation and the regulation of cadmium accumulation in Brassica chinensis. Environ. Sci. Pollut. Res. 26, 24532-24541. doi: 10.1007/s11356-019-05705-x

Zhang, D., Dong, T., Ye, J., and Hou, Z. (2017). Selenium accumulation in wheat (Triticum aestivum $L$ ) as affected by co-application of either selenite or selenate with phosphorus. Soil Sci. Plant Nutri. 63, 37-44. doi: 10.1080/00380768.2017. 1280377

Zhang, H., Feng, X., Chan, H., and Larssen, T. (2014). New insights into traditional health risk assessments of mercury exposure: implications of selenium. Environ. Sci. Technol. 48, 1206-1212. doi: 10.1021/es4051082

Zhang, L., Hu, B., Li, W., Che, R., Deng, K., Li, H., et al. (2014). OsPT2, a phosphate transporter, is involved in the active uptake of selenite in rice. New Phyto. 201, 1183-1191. doi: 10.1111/nph.12596

Zhang, H., Feng, X., Larssen, T., Qiu, G., and Vogt, R. D. (2010). In inland China, rice, rather than fish, is the major pathway for methylmercury exposure. Environ. Health Perspect. 118, 1183-1188. doi: 10.2307/20749145

Zhang, L., Hu, B., Deng, K., Gao, X., Sun, G.-X., Zhang, Z., et al. (2019). NRT1.1B improves selenium concentration in rice grains by facilitating selenomethinone translocation. Plant Biotechnol. J. 17, 1058-1068. doi: 10.1111/pbi.13037

Zhang, Z. (2019). Selenium Speciation and Selenium-Cadmium Interaction in Staple Crops. Ph. D thesis, China University of Geosciences, Wuhan.

Zhao, F., McGrath, S. P., and Meharg, A. A. (2010). Arsenic as a food chain contaminant: mechanisms of plant uptake and metabolism and mitigation strategies. Annu. Rev. Plant Biol. 61, 535-559. doi: 10.1146/annurev-arplant042809-112152

Zhao, X., MItani, N., Yamaji, N., Shen, R. F., and Ma, J. F. (2010). Involvement of silicon influx transporter OsNIP2;1 in selenite uptake in rice. Plant Physiol. 153, 1871-1877. doi: 10.1104/pp.110.157867

Zhao, Y., Hu, C., Wu, Z., Liu, X., Cai, M., Jia, W., et al. (2019). Selenium reduces cadmium accumulation in seed by increasing cadmium retention in root of oilseed rape (Brassica napus L.). Environ. Exp. Bot. 158, 161-170. doi: 10.1016/ j.envexpbot.2018.11.017

Zhou, X., Li, Y., and Lai, F. (2018). Effects of different water management on absorption and accumulation of selenium in rice. Saudi J. Biol. Sci. 25, 11781182. doi: 10.1016/j.sjbs.2017.10.017

Zhou, X., Yu, S., Wang, W., Chang, H., and Zhou, Y. (2014). Effects of application of selenium in soil on the formation of root surface iron plaque and mercury uptake by rice plants (In Chinese). J. Southwest Univ. 36, 91-95.

Zhou, X., Yu, S., and Xie, D. (2015). Effects of pH and three kinds of anions on selenium absorption and desorption in purple soil (In Chinese). Acta Pedol. Sin. 52, 1069-1077. doi: 10.11766/trxb201409290496

Zhou, X.-B., Gao, A.-X., Lai, F., Zhang, C.-M., and Xu, W.-H. (2017a). The role of selenium in soil: effect on the uptake and translocation of arsenic in rice (Oryza sativa L). Int. J. Agric. Biol. 19, 1227-1234. doi: 10.17957/IJAB/15. 0430

Zhou, X. B., Gao, A. X., Zhang, C. M., Xu, W. H., and Shi, X. J. (2017b). Exogenous selenium alleviates mercury toxicity by preventing oxidative stress in rice (Oryza sativa) seedlings. Int. J. Agric. Biol. 19, 1593-1600. doi: 10.17957/IJAB/ 15.0476

Zhou, X. B., Lai, F., Zhang, C. M., Gao, A. X., and Xu, W. H. (2017c). Pathways of selenium to grain relative to form of selenium and variety of rice (Oryza sativa L.). Acta Pedol. Sin. 54, 1251-1258. doi: 10.11766/trxb201701190463 
Zhou, X. B., and Li, Y. Y. (2019). Effect of iron plaque and selenium on mercury uptake and translocation in rice seedlings grown in solution culture. Environ. Sci. Pollut. Res. 26, 13795-13803. doi: 10.1007/s11356-018-3066-Z

Zhou, X.-B., Shi, W.-M., and Zhang, L.-H. (2007). Iron plaque outside roots affects selenite uptake by rice seedlings (Oryza sativa L.) grown in solution culture. Plant Soil 290, 17-28. doi: 10.1007/s11104-006-9072-9

Zhu, Y.-G., Pilon-Smits, E. A. H., Zhao, F.-J., Williams, P. N., and Meharg, A. A. (2009). Selenium in higher plants: understanding mechanisms for biofortification and phytoremediation. Trends Plant Sci. 19, 436-442. doi: 10. 1016/j.tplants.2009.06.006
Conflict of Interest: The authors declare that the research was conducted in the absence of any commercial or financial relationships that could be construed as a potential conflict of interest.

Copyright $\odot 2020$ Zhou, Yang, Kronzucker and Shi. This is an open-access article distributed under the terms of the Creative Commons Attribution License (CC BY). The use, distribution or reproduction in other forums is permitted, provided the original author(s) and the copyright owner(s) are credited and that the original publication in this journal is cited, in accordance with accepted academic practice. No use, distribution or reproduction is permitted which does not comply with these terms. 